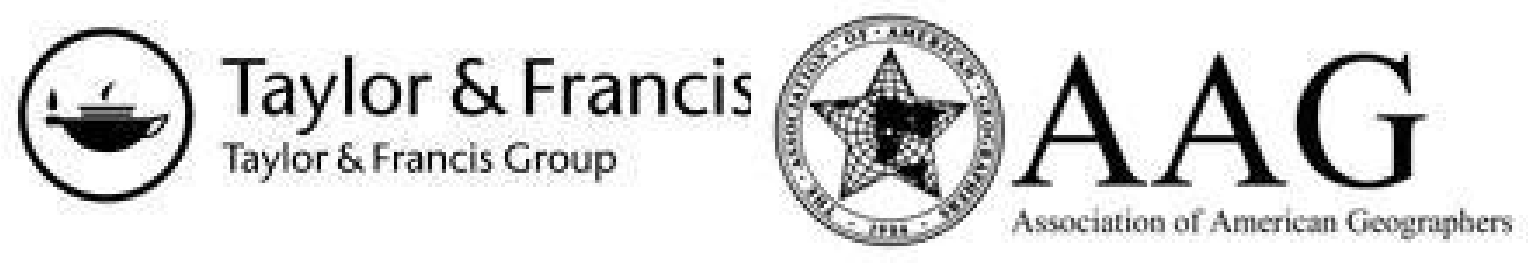

The Weather Element in American Climates

Author(s): Robert de C. Ward

Source: Annals of the Association of American Geographers, Vol. 4 (1914), pp. 3-54

Published by: Taylor \& Francis, Ltd. on behalf of the Association of American Geographers

Stable URL: http://www.jstor.org/stable/2560740

Accessed: 07-07-2016 10:35 UTC

Your use of the JSTOR archive indicates your acceptance of the Terms \& Conditions of Use, available at

http://about.jstor.org/terms

JSTOR is a not-for-profit service that helps scholars, researchers, and students discover, use, and build upon a wide range of content in a trusted digital archive. We use information technology and tools to increase productivity and facilitate new forms of scholarship. For more information about JSTOR, please contact support@jstor.org.

Taylor \& Francis, Ltd., Association of American Geographers are collaborating with JSTOR to digitize, preserve and extend access to Annals of the Association of American Geographers 


\title{
THE WEATHER ELEMENT IN AMERICAN CLIMATES
}

\author{
ROBERT DE C. WARD
}

\section{CONTENTS}

The Weather Element in the Study of Climate................ 3

General Relations of Weather and Climate................ 3

Outline of this Discussion.......................... 4

Cyclonic and Anticyclonic Control of our own Weather and Climate.. 5

Our Winter Storm Control......................... 5

Our Summer Diurnal Control........................ 6

The Combined Cyclonic and Solar Controls of our Spring and Autumn 7

Paths of Cyclones and Anticyclones in the United States............ 7

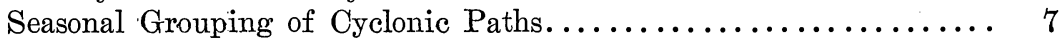

Winter Cyclonic Paths............................ 8

Seasonal Variations of Storm Paths and of Weather Types........ 10

Paths of Anticyclones in the United States................ 10

Summer Cyclonic Paths........................... 12

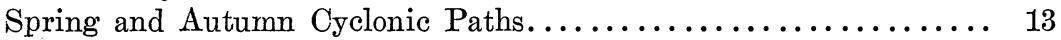

Regional and Seasonal Weather Types of the United States: General... 14

The Ideal as compared with the Actual Cyclone............. 14

Cyclonic Weather Controls in Different Sections.............. 15

Regional and Seasonal Weather Types of the Eastern United States..... 16

Winter Weather Types of the Eastern United States........... 16

Summer Weather Types of the Eastern United States........... . 29

Spring Weather Types of the Eastern United States........... 30

Autumn Weather Types of the Eastern United States........... 31

Curves illustrating Weather Types of the Northeastern. United States 34

Each Section has its own Weather Types.................. 37

Regional and Seasonal Weather Types of the Western United States..... 40

Winter. Weather Types of the Pacific Coast................ 40

Summer Weather Types of the Pacific Coast............... 46

Winter Weather Types of the Western Interior Province........ 51

Summer Weather Types of the Western Interior Province....... 52

Winter and Summer Weather Types of the Great Plains......... 53

The Weather Element in the Study of Climate.-General Relations of Weather and Climate.-Climate is the average of weather. Careful records of weather, continued for many years, give climatic averages. $^{1}$ In the Temperate Zones the weather is largely controlled by a succession of cyclones and anticyclones, more or less irregular in their occurrence; uncertain in their progression and duration, and

${ }^{1}$ A full description of a climate is given when certain numerical data, carefully corrected, summarized, and compared by well-known methods, are tabulated in a standard form (see Hann: Handbuch der Klimatologie, Vol. 1, 2d ed., 1897. Translated by R. DeC. Ward). 
differing considerably in their characteristics. Hence our weather changes are correspondingly irregular, uncertain, and diverse. The nature of these changes depends on the degree of development; the velocity of progression; the track; and other conditions of the disturbance which produces them. Of weather types there is an almost endless variety. Their detailed study belongs under Meteorology. Yet these types give our climates their distinctive characters, to a large extent determining the amount and the distribution of temperature; of precipitation; of humidity; of cloudiness. A general understanding of the nature of the cyclonic and anticyclonic control is, therefore, essential to a proper appreciation of our climate. Anyone who seriously attempts to study the climatology of the United States should have a series of weather maps in one hand, and a set of climatic charts of the country in the other. He will very soon realize that the better his understanding of the former, the more intelligent is his appreciation of the latter.

The essence of this cyclonic control is its irregularity. It is obvious, therefore, that its effects upon all the meteorological elements must largely disappear when the conventional time units are taken as the basis for averaging climatic data. Annual, monthly, diurnal averages of the different climatic elements, when given numerically, or even when charted, are therefore often misleading. They give but a lifeless picture. They do not show how and why the conditions which they aim to represent were really brought about. It is the irregular weather changes from day to day which give most of our climates their real character, affecting our activities, crops, comfort, and health. ${ }^{2}$ The average or normal weather of a season, a month, or even a day, is known for much of our country. It seems as if we could thus make long-range forecasts. But average weather is not what may actually happen. And it is the actual, not the normal, which we really experience.

Outline of this Discussion.-We must, therefore, try to picture to ourselves the series of weather types which, varying seasonally and regionally, make up the average sum-total of what we call our climate. The more pronounced types have a certain well-marked individuality, and a more or less systematic recurrence. As they depend so largely upon the passage of cyclones and anticyclones, we must first familiarize ourselves with the movements of these areas across the United States. This will lead us to an understanding of the more marked weather

\footnotetext{
${ }^{2}$ For a fuller discussion of this subject, see R. DeC. Ward: "Suggestions concerning a more Rational Treatment of Climatology," Report VIII Int. Geogr. Cong., Washington, D. C., 1905, 277-293 (contains numerous references) ; W. G. Reed, Jr.: "The Study of Phenomenal Climatology," Quart. Journ. Roy. Met. Soc., Vol. 36, 1910, 39-48.
} 
changes associated with their passage. And, finally, we shall illustrate a few of the most marked and typical weather types by means of a series of curves and simplified weather maps.

Cyclonic and Anticyclonic Control of Our Own Weather and Climates.-Most of the United States is well within the belt of prevailing westerly winds, one of whose most marked characteristics is the continuous procession of cyclonic and anticyclonic disturbances which keeps marching eastward in a great spiral circuit around the North Pole. Over the Temperate Zones, as a whole, there is thus a great ring of stormy weather, oscillating poleward and equatorward as the sun moves to and fro in the course of its regular migration. Northward, across the United States, to our northern border, swings this great storm belt as the summer sun comes north of the equator. Southward it swings in winter, following the declining sun, covering the country even to the Gulf of Mexico. Scattered through the southern quadrants of our cyclonic storms, especially during the warmer months, come more local disturbances-thunderstorms and tornadoes. There is, thus, a second belt of local storms, south of the general eyclonic storm belt. This, also, swings back and forth seasonally, covering practically the whole country in summer, and being carried well into and even across the southern States in winter.

Our Winter Storm Control.-The quality of our weather types varies seasonally and geographically. These types result from a combination, more or less irregular, of periodic, diurnal elements, under the control of the sun, and of non-periodic, cyclonic and anticyclonic, elements. In winter, when practically the whole country is under the influence of the storm belt; when the sun is low and the days are short, the non-periodic control is everywhere strongest. Local conditions of heat and cold largely become subordinate to the general control by the cyclone and anticyclone, which import winds and weather from a distance. The irregular changes from clear to cloudy; from warmer to colder; from dry air to snow or rain, extend over large areas, and show but little diurnal control. Our storms are not only more widely distributed over the country in winter, but are then larger, more frequent, more violent, and move faster. Hence all our changes, of wind, temperature and weather occur oftener, are more sudden, and more emphatic during that time. Our northern, and especially our northeastern States, being most frequented by our winter storms, have the most changeable weather, the alternation between fair and stormy being repeated with considerable regularity and frequency. This cycle of cyclonic changes is run through in about two to four days. With increasing distances to the south and west, the general storm control weakens; less cloudy and stormy weather occurs, and the temperature 
changes are less sudden and less marked. Thus it is that our southern and especially our southwestern States have on the whole more settled, " better," winter weather, and more uniform temperature-conditions than the northern States. New Mexico, Arizona, western Texas, southern California, for example, are so far removed from our most frequented storm belts, and their own cyclones are on the whole so weak, that they enjoy an abundance of sunshine, have little precipitation, and that mostly in brief showers. Our Gulf States, and especially Texas, are, however, exposed to occasional invasions of severe cold from the north, when winter cyclones, traveling well to the south, are followed by cold waves. These cold waves, if they come early in the winter, or last long, may result in great damage to crops.

Our Summer Diurnal Control.-From the irregular storm control which is so powerful in winter, to the dominant solar control of summer is a characteristic change which, year after year, is accomplished with the orderly sequence of the seasons. In summer, when the general storm belt swings to the north, followed, on its southern side, by the thundershower belt, the cyclonic element in our weather changes is weakest. The cyclone, with its irregular control over all our weather elements, gives way to the sun. In place of the turbulent atmospheric circulation of the colder months we have the gentler movements of the warmer. The temperature-distribution the country over is remarkably uniform. The prevailing temperatures are high; the variations small; the gradients weak. The dominant weather types are associated with the regular changes from day to night. Periodic, diurnal phenomena replace non-periodic, cyclonic phenomena. Cumulus clouds, especially noticeable on days which follow rainfalls; diurnal variations in temperature and in wind velocity; afternoon thunderstorms, recurring in spells with considerable regularity, characterize the warmer months over most of the country and present an analogy with tropical conditions. Cyclonic and anticyclonic spells of hotter or cooler, rainy or dry weather, with varying winds differing in the temperatures and moistures which they bring, serve to break the regularity of the simple, diurnal, sun-controlled types. Summer is the season of weak, poorly developed, slow-moving storms, mostly following our northern borders; of few nimbus clouds; of local rather than widespread general rains; of relatively small changes of temperature; of light and variable winds. The squall winds of our passing thunderstorms, and the violent inrushing blasts of our tornadoes, are local and temporary interruptions of the generally calm and peaceful regime of our summer weather. Our southern and western States, being well removed from the storm belt, have a succession of typical "settled," diurnal changes, day after day, with few general rains, but share with 
most of the country the local disturbances characteristic of the thunderstorm belt. The northern tier of States, east of the Rocky Mountains, being at the southern margin of the summer storm belt, experiences the irregular changes which result from the eastward progression of summer cyclones. These changes are, however, far less marked than in winter. They are often little more than a series of warmer and cooler spells, often repeated fairly systematically in a period of roughly about four to eight days; with thunderstorms and long periods of uniform temperatures interspersed.

The Combined Cyclonic and Solar Control of Our Spring and Autumn.-Spring and autumn are transition seasons, and have their own transitional weather types. In spring, the growing diurnal element is marked by the increasing importance of local controls; by the appearance of convectional phenomena such as cumulus clouds and "April showers;" by the struggle between cyclonic and solar controls of temperature, now one, now the other, being paramount, but the latter gaining, the former losing. The storm control becomes increasingly uncertain and weaker; the storm movements are slower and more erratic. Irregularly, spasmodically, is the transition from winter to summer accomplished. Wintry spells are interpolated between summer spells. But the latter become more marked, last longer, advance further northward, as the former come less frequently, are less emphatic, and gradually withdraw to higher latitudes. March is usually a turbulent and unpleasant month in northeastern sections, with quick alternations of wintry conditions and of types indicative of approaching summer. ${ }^{3}$

With the passing of summer into autumn the sun's rays become more and more oblique, and weaken; the temperature falls; the days grow shorter; the control of our weather passes gradually but irregularly from the sun back again to the cyclone; from the mildness of summer to the turbulence of winter. The decrease in diurnal phenomena, such as local thunderstorms, is an autumnal characteristic. As autumn draws to its close, the irregular cyclonic regime of winter is once more established. It is in the north and east, close to the most frequented storm belts, that the cyclonic control continues longest in spring. So it is also in these same districts that the storm control first makes itself felt in autumn.

Paths of Cyclones and Anticyclones in the United States. Seasonal Grouping of Cyclonic Paths.-We may now turn to a some-

${ }^{3}$ Professor 0. L. Fassig has shown that the types of weather, storm paths, and amount and character of precipitation in March, depend upon the relations and development of the continental, the Atlantic and the Pacific anticyclones ("Types of March Weather in the United States," Amer. Journ. Sci., 4th Ser. Vol. 8, No. 47, Nov., 1899, 319-340). 
what closer examination of the regions over which our cyclones move most frequently. It is a mistake to picture to ourselves any rigid system of clearly-defined storm "tracks." There are, rather, certain broad belts or districts over which our cyclones travel more frequently than elsewhere. For our present climatological purpose it is best to generalize, showing these most frequented regions as broad belts, and realizing that there is no very close and definite relation of our cyclones to these paths. For the sake of simplicity we divide the year into three parts, as suggested by Professor F. H. Bigelow, whose careful study of our storm tracks is our best source of information on this subject. $^{4}$ Each of these divisions has its own more or less distinctive

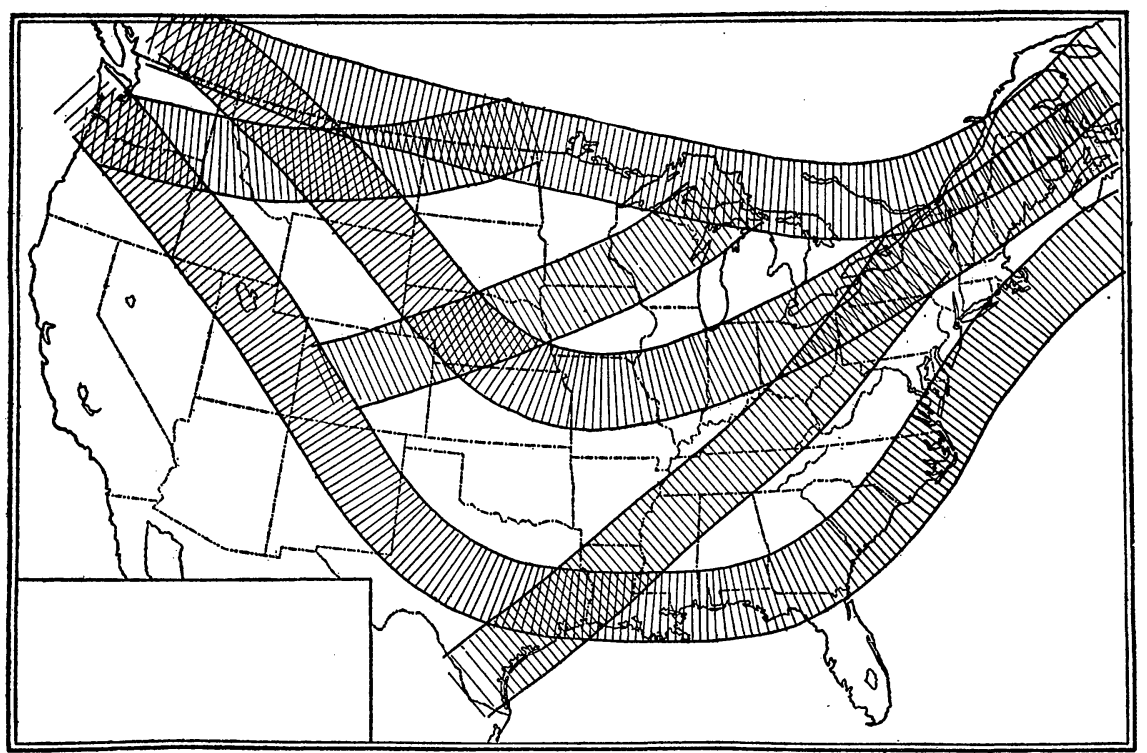

FIG. 1.-Generalized Winter Storm Paths.

meteorological characteristics, cyclonic and anticyclonic belts, and weather types. December, January, February and March are winter; June, July, August and September are summer; April and May, and October and November, are spring and autumn, respectively.

Winter Cyclonic Paths.-Most of our winter cyclones appear first on our weather maps in the region north of Montana ("Alberta Type"), and are probably offshoots from the great cyclone over the

${ }^{4}$ F. H. Bigelow, "Storms, Storm Tracks and Weather Forecasting," U. S. Weather Bureau, Bulletin No. 20, Washington, D. C., 1897. A. J. Henry, "Climatology of the United States," U. S. Weather Bureau, Bulletin Q, Washington, D. C., 1906. Professor Henry lays much emphasis upon cyclonic and anticyclonic controls of American weather. Professor Bigelow's and Professor Henry's discussion has been followed in the description of storm paths, but the charts are the present writer's. 
North Pacific Ocean. Thence they travel southeast and east along a path which is known as the "Northern Circuit," across the Great Lakes and down the St. Lawrence Valley to the Atlantic Ocean. The time usually occupied for this journey is between three and four days. ${ }^{5}$ Some of these storms loop southward over the eastern Rocky Mountain slope to Iowa and Missouri, cross the Mississippi Valley, and then move northeast to the northern circuit, occupying about three days to the Lower Lakes. Towards spring, occasional storms of this type are deflected south to the Gulf, under the influence of wellmarked anticyclones moving southeast from the region north of Montana. When a new storm comes in from the northwest there is frequently an anticyclone over the southern or central States, moving east slowly, and a retreating cyclone in the northeast.

From the northern Pacific coast comes a considerable procession of storms ("North Pacific Type") which move eastward on the northern circuit. Some of this group, especially in the late winter, make a wide swing southeastward (roughly with eastern North Dakota as a centre and with a radius of 1,200 miles, more or less, in length) across the Basin Region, New Mexico and western Texas, and then northeast to the Gulf of St. Lawrence. This southern storm belt is known as the "Southern Circuit." The cyclones of the North Pacific type make their southward loop under the control of high pressures over the northern central and the Missouri valleys. For the transcontinental journey, from the Pacific to the Atlantic, about four days are needed, this being, it will be observed, a little more rapid than the rate of travel of a through express train making the same trip. The long swing over the southern circuit is usually made at such high velocity that the time occupied on the journey is about the same as when the northern circuit is followed. Other storms of the North Pacific type make a more moderate loop to the southeastward over the Plateau region, crossing the Rocky Mountains between latitudes $35^{\circ}$ and $45^{\circ}$, and then moving northeast across the Lakes.

From in or near Colorado ("Colorado Type") comes a group of storms which usually joins the northern circuit in the Lake region; ${ }^{6}$ or may travel eastward on the southern circuit.

From Texas and the Gulf of Mexico another group moves northeast, west of the Appalachians, across the central valleys to the Lower Lakes, and thence eastward down the St. Lawrence Valley; or, taking the outside track east of the Appalachians, travels along the Atlantic coast to the Maritime Provinces as coast storms. The journey to

${ }^{5}$ To eastern Dakota, 1 day; Lake Superior, 2 days; middle St. Lawrence Valley, 3 days.

${ }^{\circ}$ One day to Illinois; 2 days to northern New York; 3 days to the Gulf of St. Lawrence. 
New England is accomplished in about two days, but an anticyclone on the Gulf of St. Lawrence may delay the progress of the storm a day or two. As pointed out by Professor F. H. Bigelow, the Texas ("Texas" or "Southwestern Type") storms have much in common with the Colorado type, just noted, but the whole pressure system of the former is about a day's journey farther along. Storms from the Gulf of Mexico ("Gulf Type") start even farther east on the southern circuit than the Texas type. And some "coast storms" appear on the southern Atlantic coast and move northeast.

The larger facts of our winter storm movements stand out clearly: the two main circuits, northern and southern; the "spur tracks" leading from one to the other; the marked southward looping; the convergence of all the storm paths toward the northeast. This northeastern section must, obviously, have the most changeable weather in the United States.

Seasonal Variations of Storm Paths and of Weather Types.-These storm paths themselves, and the number of storms which follow given paths, are not fixed. They vary somewhat from year to year, and probably also in longer periods. Such variations control the character of our seasonal weather types. The types normally characteristic of the season may thus be more or less completely reversed, or interrupted. If we depend solely upon the usual monthly averages of temperature and rainfall, these seasonal variations in weather types are often obscured. It is only by reference to the daily weather maps that the actual conditions can be understood. If more winter storms follow the southern circuit there is likely to be unusually cold weather east of the Rocky Mountains. If more winter storms follow the northern paths, there are likely to be more southerly winds, higher temperatures, and fewer and briefer interruptions by cold northwesterly winds over the southern States. The controls of such seasonal variations in storms and storm tracks are to be sought in the development and location of the larger, permanent, areas of high and low pressure over the continent and also over the adjacent oceans.

Paths of Anticyclones in the United States.-The movements of our anticyclones are closely associated with the movements of our cyclones, and the quality of our weather largely depends upon the particular combinations, in position, development, and character, of these high and low pressure areas. The main anticyclonic paths are strikingly similar to those of the cyclones, the general tendency of the former being to run more southerly.

There are two places of origin for our anticyclones, and two main paths, as shown in Fig. 2.7 They come either (1) from the north-

\footnotetext{
${ }^{7}$ The paths here shown are those given by Professor Bigelow.
} 
west, outside of our own territory in western Canada, entering the United States near the 115th meridian, or (2) from the Pacific Ocean west of California. The latter are probably offshoots from the permanent high pressure area of the North Pacific. The first group move (a) somewhat southerly and then easterly along our northern boundary, crossing the Lake region to the Atlantic coast or the Gulf of St. Lawrence, or (b) southeast from their place of origin, along the Rocky Mountain slope to the Gulf States, thence east to the southern Atlantic coast near Florida, perhaps continuing northeast to the Gulf of St. Lawrence.

The second group, from the California coast, also generally follow one of two broad paths. They travel either (a) northeast along the

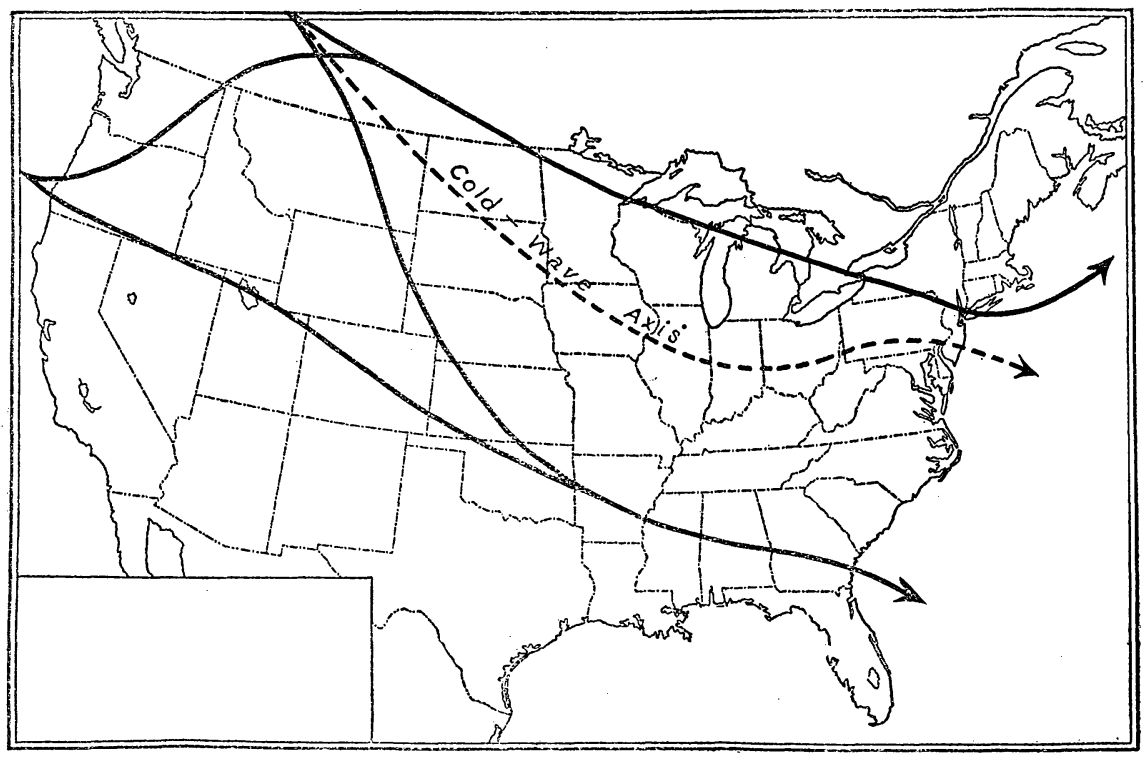

Frg. 2.-Generalized Anticyclonic Paths (after Bigelow).

Pacific slope to Washington and Oregon, and then along the northern circuit to the Atlantic coast, or (b) southeast from California to the southern Atlantic coast, crossing the mountains near Great Salt Lake. Anticyclones of this second group are limited to the warmer months, between April and September. From the northern to the southern circuit there are "spur tracks," as along the eastern Rocky Mountain slope, and across the northern plateau from Washington to Montana. Some of the relations of these anticyclonic paths to weather types in different parts of the country will be considered later. In general, the winter anticyclones are well marked, and, although stationary for long periods over the Plateau and Basin region, as a whole show fairly well defined movements along the usual paths. In summer, on the 
other hand, the high pressure areas are generally much less emphatic, and have a much greater tendency to wander about aimlessly.

Summer Cyclonic Paths.-A comparison of Fig. 3, showing the generalized summer storm paths, with Fig. 1, showing the winter storm paths, will serve to emphasize the striking difference between these two seasons in the matter of cyclonic control of weather. In summer, our prevailing weather conditions are best described as " flat" and "stagnant." Our cyclones-generally mild and gentle in character and not bringing widespread rains-travel on the northern circuit, with "feeders" from the middle-eastern slope of the Rocky Mountains, and an occasional Atlantic coast storm or West Indian

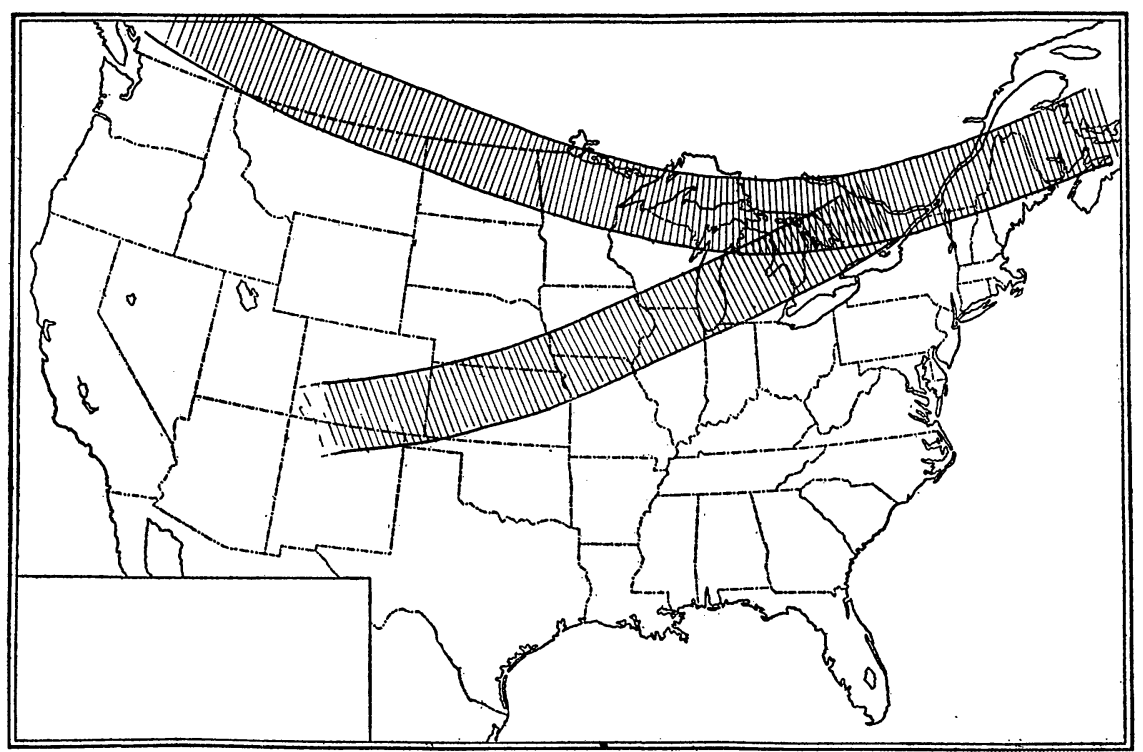

FIg. 3.-Generalized Summer Storm Paths.

hurricane. Storms rarely come directly from the northern Pacific coast. In midsummer, this group even disappears entirely. There is much less southward looping than in winter. So weak and poorly developed are many of our summer cyclones that, after wandering about indefinitely for a time, they often fade away before reaching the Gulf of St. Lawrence. The highs, also, are weaker and less emphatic than in winter.

A comparatively rare, but important type of late summer storms includes the West Indian Hurricanes. These, moving in from the east or northeast at about Lat. $25^{\circ} \mathrm{N}$, recurve toward the north, and usually follow the Atlantic coast to Nova Scotia. Sometimes, as in the case of the Galveston storm of September 8, 1900, they cross the 
Gulf of Mexico to the west, and then travel northward across the central valleys. The usual path of these hurricanes is shown on Fig. 4, for the months of October and November, rather than on Fig. 3, because they are too infrequent in summer to justify their inclusion in so highly generalized a chart as Fig. 3. West Indian hurricanes are not regular or marked weather controllers in either summer or autumn.

Spring and Autumn Cyclonic Paths.-The storm paths for spring and autumn may conveniently be generalized together (Fig. 4). In both seasons, our cyclones are more or less erratic, but their southward looping is seen to be less marked than in winter and more marked

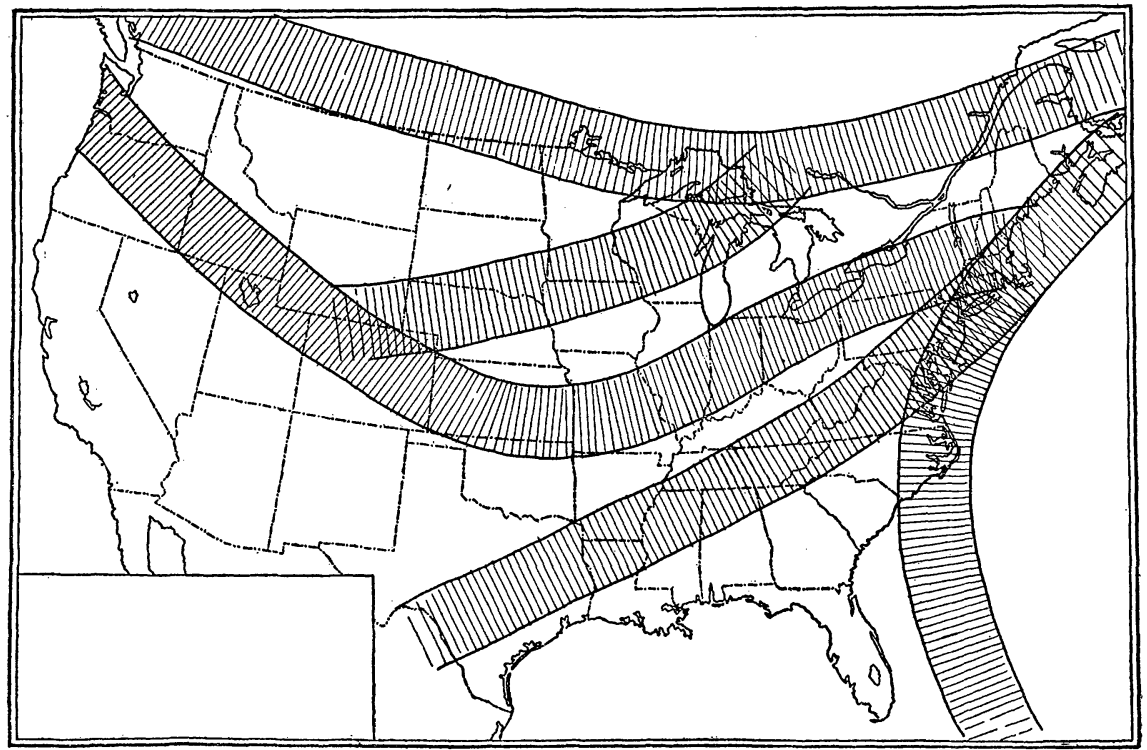

Frg. 4.-Generalized Spring and Autumn Storm Paths.

than in summer. The velocity of travel in these transition seasons is less than in winter. Thus, at the end of April, storms of the Alberta type, on the northern circuit, take about one extra day for their eastward journey. In April, the North Pacific type storms, when deflected far to the south, make their journey to the Gulf of St. Lawrence in about five days. This is also the time taken by those of the Colorado type. Those from Texas also take an extra day (3 days) to reach the Gulf of St. Lawrence. In spring, a number of storms which are important for the eastern United States come from the middle-eastern Rocky Mountain slope, and move northeast across the Lake region and New England. One of the characteristics of autumn is the increase in the number of anticyclones from the region north of Montana and from still further west, and the occasional 
passage of a tropical cyclone (West Indian hurricane) along the Atlantic coast, referred to in the previous paragraph.

Regional and Seasonal Weather Types of the United States: General.-The Ideal as compared with the Actual Cyclone.-A diagram of the 'average distribution of the weather elements around an ordinary cyclone,' such as is printed in many meteorological text-books, is misleading. The impression made thereby is that cyclones are always like the ideal one shown in the figure. It seems as if, when a cyclone moves across country, we should imagine this ideal diagram, presumably representing the actual weather conditions in that eyclone, to be drawn eastward across a map of the United States as if it were hung on a wire and pulled by a string. This is a very misleading conception. Cyclones differ greatly from one another. Each has its own peculiar characteristics, although they all conform to the same general laws. They differ in character with the seasons. They differ with the topography and general physical conditions of the region over which they move. They differ with the varying conditions of other accompanying, and with the effects of preceding, cyclones and anticyclones. Therefore, if we are to gain an accurate and vivid impression of the weather conditions which make up and control our climates we must next examine our weather types as they vary with the season and with the district.

In making such a study it naturally suggests itself that we follow one "typical" cyclone, or anticyclone, across country, noting its control over the weather in the successive sections which it passes on its eastward march. This is not practicable. For it is difficult, if not impossible, to find cases of "typical" cyclones, following "typical" paths with average velocities, and controlling the regional weather conditions in a "typical" way all across the United States. Individual type weather maps are far less satisfactory for the purpose of such an investigation than broadly generalized, composite, types of conditions of the same general character. The exact weather distribution of an individual map, or of a series of individual maps, will never occur again. Moreover, maps which seem to be identical do not necessarily produce identical results. Hence, in the illustrations of regional weather types which follow (Figs. 5-24), no attempt has been made to reproduce any actual weather maps, or even any composites compiled by tracing from any number of selected maps. The effort has rather been to show the general conditions of pressure, temperature, winds and weather commonly associated with cyclunes of different groups. These charts have been compiled after a study of some hundreds of weather maps, and are, in fact, highly generalized composites, drawn free-hand. It is, manifestly, impossible within the limits of this discussion to attempt the illustration of any consid- 
erable number of weather types. The composites given below concern a few of the more common cyclonic conditions, chiefly in the eastern United States and in winter.

Cyclonic Weather Controls in Different Sections.-In general, we may naturally expect that when a cyclone is central in the Great Basin, for example, or on the eastern Rocky Mountain slope, or in New Mexico, the amount and distribution of its precipitation will be different from that when the same storm, or a similar one, is located east of the Rocky Mountains, let us say, or over the central valleys. In the first case, the enclosing mountain ranges to a large extent shut out the influence of the surrounding water bodies, and may readily be supposed to interfere with the systematic development of the cyclonic wind system; the inflowing winds in the southeast quadrant may be dry and non-rainy, or perhaps give only local showers. In the second case, coming from the Gulf of Mexico, winds in the southerly quadrant may cause widespread general rains. Again, when a cyclone approaches the Atlantic coast, a still further difference may be observed. Then the winds throughout the eastern quadrants may be coming across water surfaces (Great Lakes, Atlantic, Gulf of Mexico), there is a greater supply of moisture, and the rainfall area may be to the northeast as well as to the southeast of the centre. Thus, there is a natural difference as regards precipitation between cyclones in the western interior and in the eastern United States. In the latter, the heavy rainfalls are usually found southeast of, and at a distance of 300 miles or so from, the storm centre. In the eastern United States, from the Mississippi and Missouri valleys to the Atlantic coast, rain usually begins during the colder months with a falling barometer. In the warmer season, however, except in connection with general storms, the precipitation, in showers and thunderstorms, usually comes with the turn from falling to rising pressure. On the Pacific coast, rain generally commences with falling pressure. But during most of the time over the Plains, and in the Rocky Mountain and Plateau districts, rain does not begin until the cyclonic centre has passed by to the south or east, and the pressure is beginning to rise.

As regards their controls over temperatures, also, our low and high pressure areas differ in different parts of the country. In the east, the differences between the temperatures in front of a well-marked cyclone and those in the rear, in front of the advancing anticyclone, may be $50^{\circ}$ or $60^{\circ}$, or more, in winter. Elsewhere, as on the Pacific coast, or in the south, for example, where the physical conditions are different, and where the cyclones and anticyclones may be less emphatic, or differently associated, the temperature controls are very much less marked. 
Regional and Seasonal Weather Types of the Eastern United States.-Winter Weather Types of the Eastern United States.-The general series of weather changes during the passage of a well-developed winter cyclone and a following anticyclone over the eastern United States in winter is about as follows: a gradual clouding in advance of the storm; increasing northeasterly, easterly, or southerly winds; rising temperature, often bringing unseasonable warmth and even resulting in a thaw in northern sections; rain or snow; a change in wind direction to westerly and falling temperature, with clearing weather. If the cyclone and anticyclone are near, well-developed, and moving rapidly, this sequence is well-marked; the wind changes are distinct; the wind velocities high; the temperature-variations sudden and large; the precipitation heavy. On the other hand, all the characteristic weather types are weakened, and may attract little attention, if the cyclonic control is weak or distant. The types also vary with the location of a district to the north or south of the storm path.

In the eastern United States the cold wave is the most striking and most characteristic winter phenomenon. When our storms move rapidly, the southwestern quadrant is usually considerably warmer than the northeastern, the northwestern being the coldest. In a good typical winter case the average temperature east of the Mississippi River and south of the storm centre was $59^{\circ}$; to the west and south of the center it was $35^{\circ}$; in the northwest quadrant it was $15^{\circ}$. From a large number of observations, the writer has determined the temperature-departures in the four quadrants of well-developed winter cyclones in the eastern United States. Taking the temperature at the centre as the standard, the average departures were as follows: northwest, $-8.7^{\circ}$; northeast, $-5.6^{\circ}$; southeast, $+7.3^{\circ}$; southwest, $+26^{\circ}$. For winter anticyclones the results were: northwest, $-5.1^{\circ}$; northeast, $-3.3^{\circ}$; southeast, $+8.9^{\circ}$; southwest, $+7 .^{\circ}$. In general, the average rise of temperature in front of a winter storm in the eastern United States is not far from $10^{\circ}$, but may reach $20^{\circ}-30^{\circ}$ above the seasonal normal. Stations which happen to be on the northern side of a passing cyclone have northerly instead of southerly winds, and therefore do not experience such marked temperaturechanges as are noted at stations south of the storm path.

The rapidity and amount of fall of temperature in the rear of a retreating cyclone depends upon the development, paths, velocities and relations of the existing low and high pressure areas. In winter, when our cyclones have passed to the eastward of the Rocky Mountains, they are usually followed by anticyclones which press southward behind them from the northwest. When, for example, an energetic cyclone is moving east, along the southern circuit, and a well-marked anticyclone with low temperatures follows it, advancing 


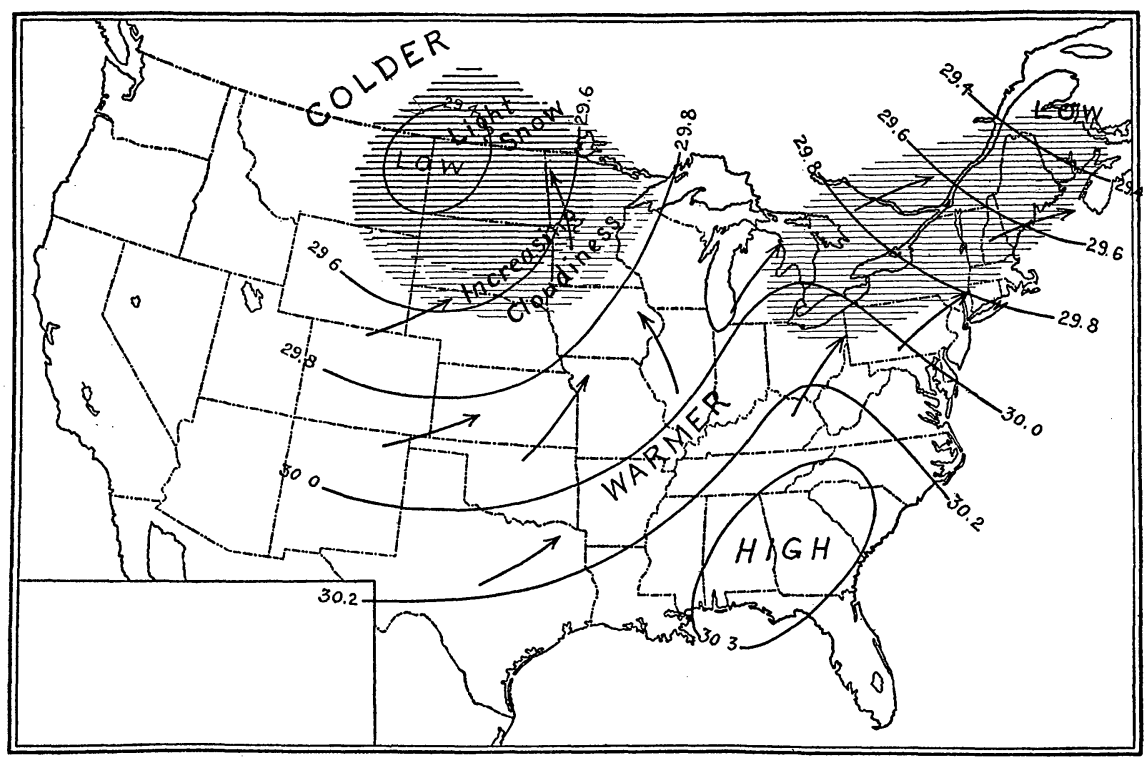

FIG. 5.-North Western (Alberta) Type, first day.

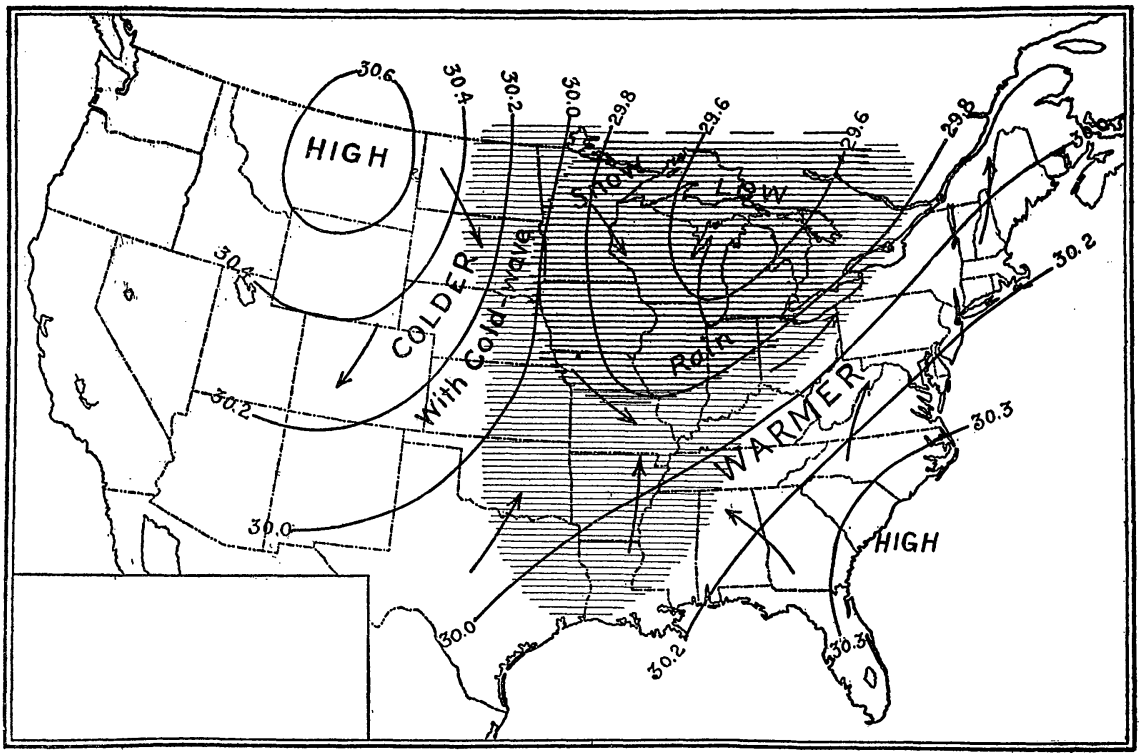

Fig. 6.-North Western (Alberta) Type, second day. 
from the northwest, the conditions are most favorable for severe cold in the southern States. If, in the absence of a low pressure area over the southern States, the anticyclone follows the northern circuit, the fall of temperature is less severe, and extends less far southward. When a high remains stationary over the northern Rocky MountainPlateau region, there is not much likelihood of severe cold waves east of these mountains. The number of possible combinations of cyclones and anticyclones in the production of more, or less, severe, and of more, or less, extended cold waves, is very large. Discussion of these combinations is out of place here. Without a preceding energetic low, an anticyclone will not bring as great a fall in temperature as

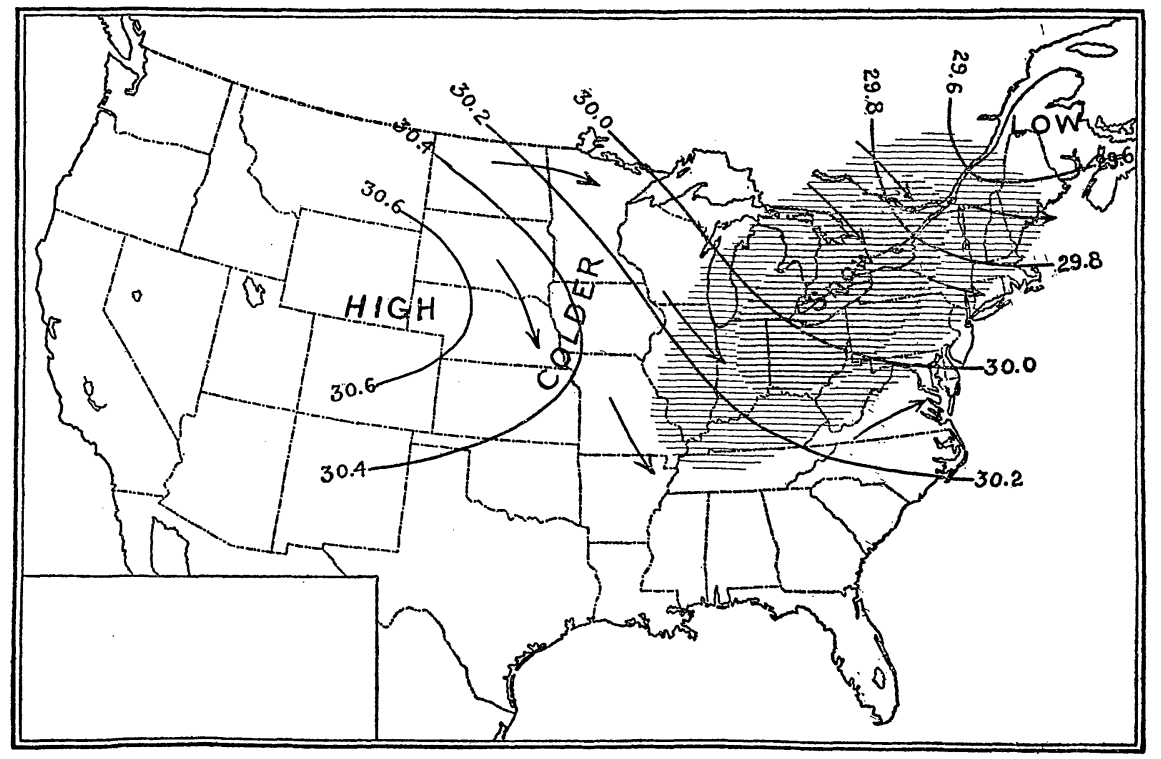

FIG. 7.-North Western (Alberta) Type, third day.

with it. The more rapid the progression of the low, other things being equal, the more rapid the fall in temperature. Cold waves in the North Atlantic States and in New England occur in the rear of a retreating cyclone, followed by a high moving east or southeast from the northern Plains. In general, there is a gradually decreasing intensity of cold when marked highs have moved from the northwest into the southern States and then turn east or northeast. Thus the eastern sections, under these conditions, may have modified cold waves.

When our winter storms of the northwestern ("Alberta") type first appear on our weather maps they usually cause little precipitation, and that mostly in the form of snow in their northern and northwestern quadrants, over the northern Rocky Mountain region. The temperature is then rising, as a rule, west of the Mississippi 
River, with southerly winds, but falling in the northwest with northerly winds, and the cloudiness is increasing over the northern Plains. In twenty-four hours, more or less, the storm, meanwhile increasing in intensity, is likely to be over the upper Lakes, attended by more precipitation, which may be in the form of heavy snows, and often by severe southerly or southwesterly gales. Over the central valleys and to the eastward the temperatures rise perhaps $20^{\circ}$ to $30^{\circ}$, and with the warmer weather come clouds and rain at the southern, and probably snow at the northern stations. Colder, clearing weatherperhaps a well-defined cold wave-follows the storm centre with northwesterly winds, overspreading the northern tier of states from the Rocky Mountains to the Lakes. On the third day the storm centre usually reaches the vicinity of the Gulf of St. Lawrence, perhaps still further increasing in energy; the area of rising temperatures with snow or rain extends to the Atlantic coast; falling temperatures with clearing northwest winds are noted across the central valleys and to the eastward. Snow, with westerly gales, often continues for some hours at stations on the lower Lakes, and storm warnings, of high southwest, west and northwest winds are frequent under these conditions along the northern Atlantic coast. As the storm centre moves off beyond the range of the weather map, the clearing and colder weather overspreads the northeastern sections. After a day or so the cold begins to moderate over the central valleys, the weather continuing fair until controlled by the next cyclone. Figures 5 to 7 illustrate weather conditions of common occurrence around a cyclone of the northwestern type during its progress across country.

Our "northwestern" storms are not our greatest rain-bringers in the eastern United States. Precipitation is generally light, and on their western side, until they reach the upper Mississippi Valley and the Lakes, when the rainfall becomes heavier and is found in the eastern quadrants, especially to the southeast of the centre. Further, these storms are generally unfavorable to precipitation over southern sections, which are likely to be outside the limits of rainfall. Extended cyclones of this type, as well as of the other types, may, however, cause stormy. weather over practically the whole country east of the Rocky Mountains, carrying their cold and their rains as far south as the Gulf of Mexico. A succession of northern circuit storms tends to cause a spell of dry weather in the south. At the same time the warm southerly winds, flowing northward over the states which lie south of the storm path, bring high temperatures to those sections. One other feature of this same type of storm is its tendency, not infrequently, to be accompanied and followed by a generally unsettled condition, extending as a long trough across the central valleys to the Gulf of Mexico. Such a pressure distribution is likely to develop 
secondary storm centres, and to lead to a somewhat prolonged period of rainy and cloudy weather over eastern sections.

Storms of the "North Pacific" type which have crossed the northern portion of the interior province, ${ }^{8}$ and then follow the northern circuit, do not differ essentially in the weather types which they produce over the eastern United States from those of storms of the Alberta type. (Figs. 5-7.) Fig. 8 illustrates a North Pacific type storm when it is controlling the conditions over the northern Pacific Slope, ${ }^{9}$ before it moves east across the mountains. From the northern circuit, in common with a number of storms of the Alberta type, some of this North Pacific group loop southwards when east of the Rocky Moun-

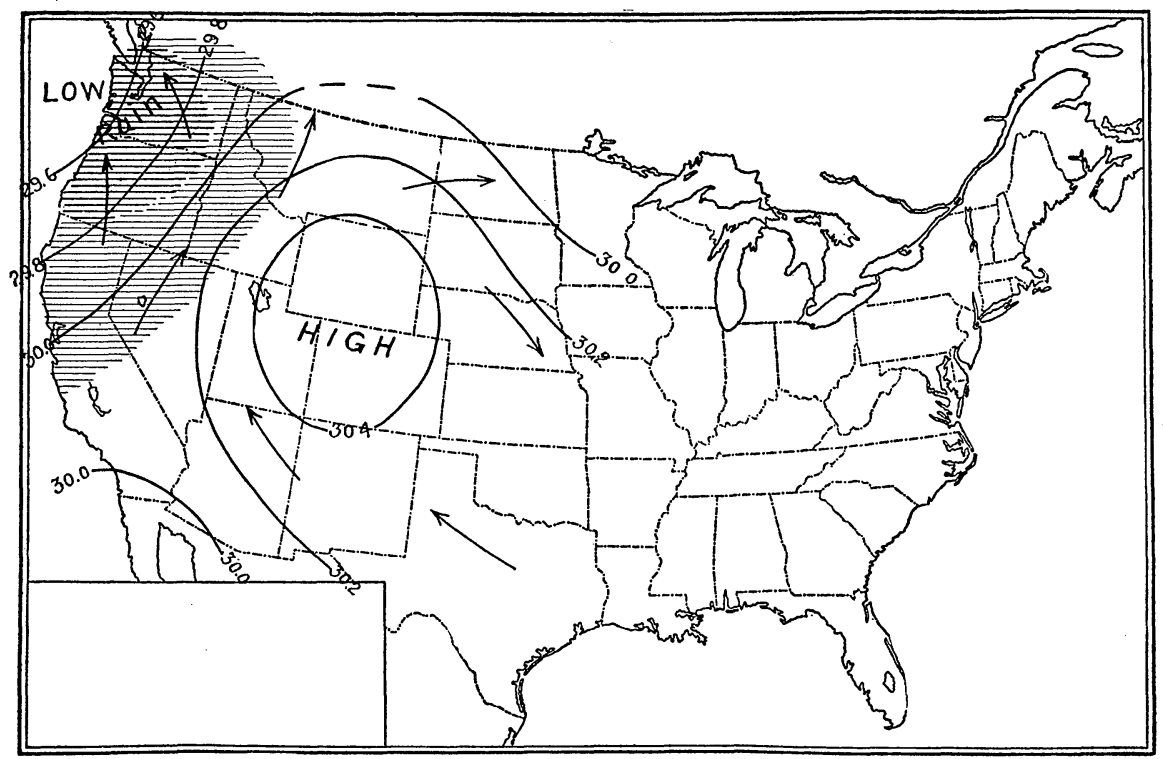

FIG. 8.-North Pacific Type, first day.

tains, and then turn northeastward to the Lakes and New England. Many North Pacific type lows do not follow the northern circuit, but loop southeastward over the central or southern part of the interior province, perhaps skirting the Gulf Coast on the southern circuit, and then moving northeasterly up the Mississippi Valley (Figs. 9 to 12), or crossing the Rocky Mountains farther north (lat. $35^{\circ}-45^{\circ}$ ) and then traveling northeast. The regional weather types differ according to the path and the special characteristics of each cyclone. When the storm follows a low latitude, perhaps crossing northern Texas and Oklahoma, or Louisiana, before turning more directly

8 "Interior Province" is that portion of the United States between the Rocky Mountains and the Sierra Nevada-Cascades.

${ }^{9}$ See page 40 . 


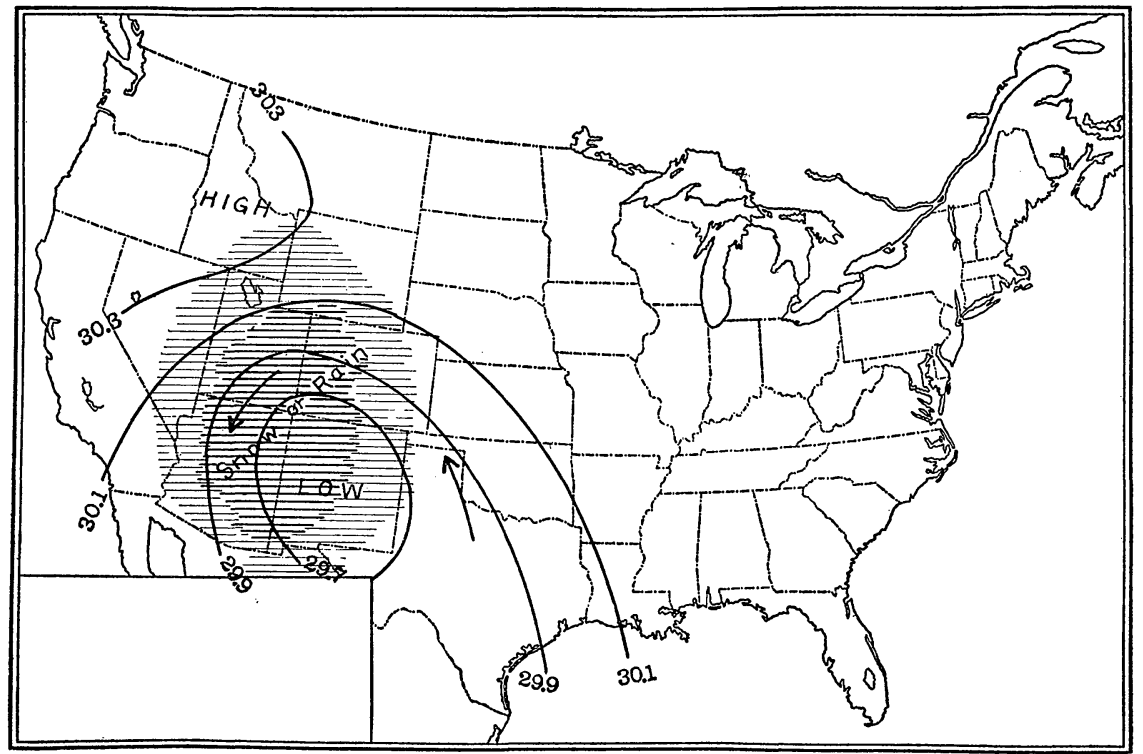

Fig. 9.-North Pacific Type (southern circuit), second day.

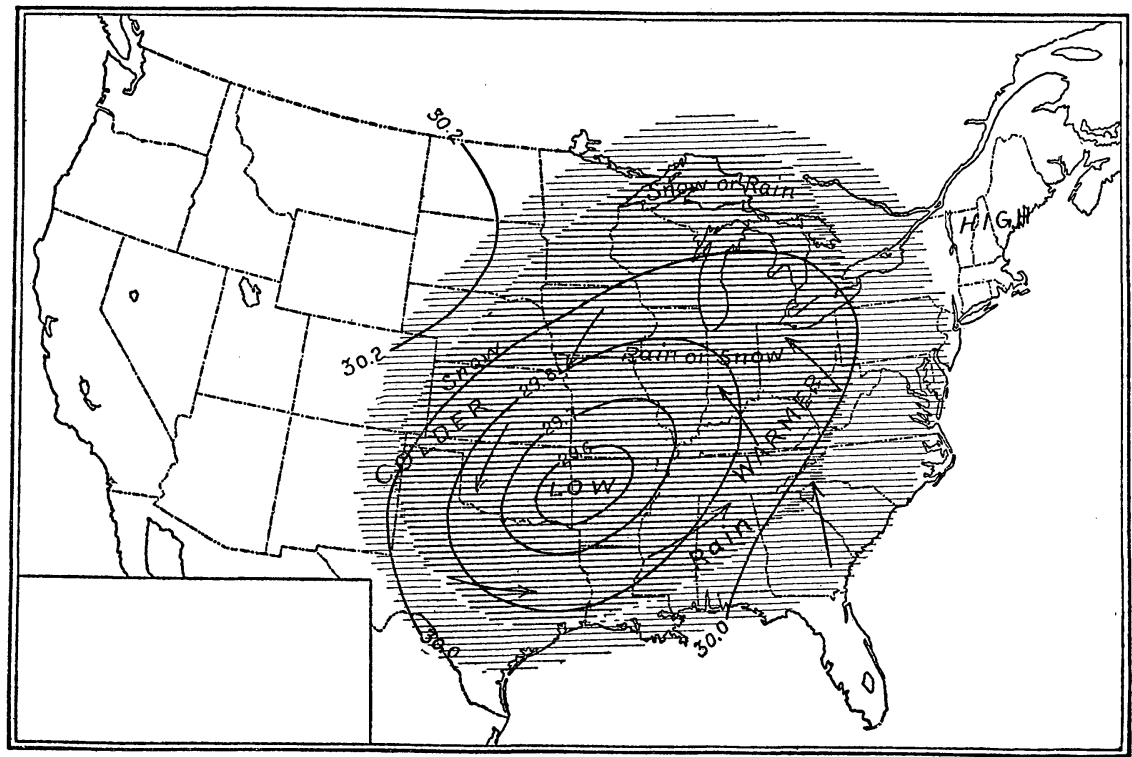

Frg. 10.-North Pacific Type (southern circuit), third day. 


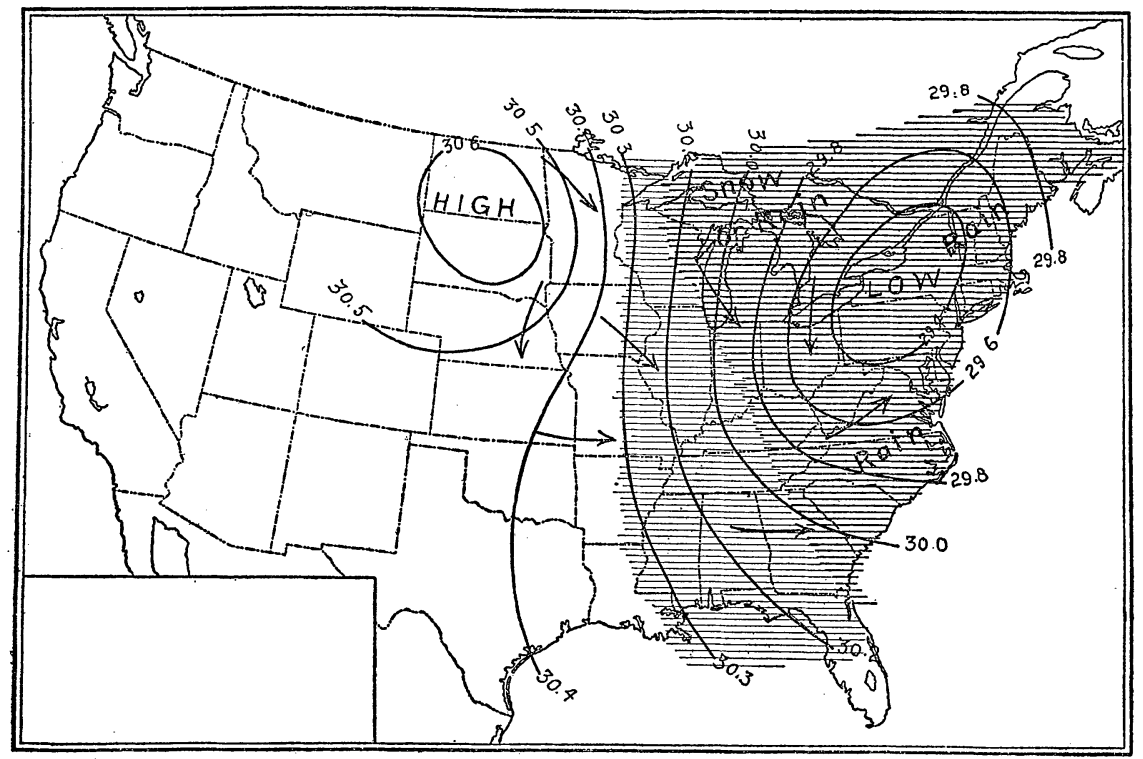

FIg. 11.-North Pacific Type (southern circuit), fourth day.

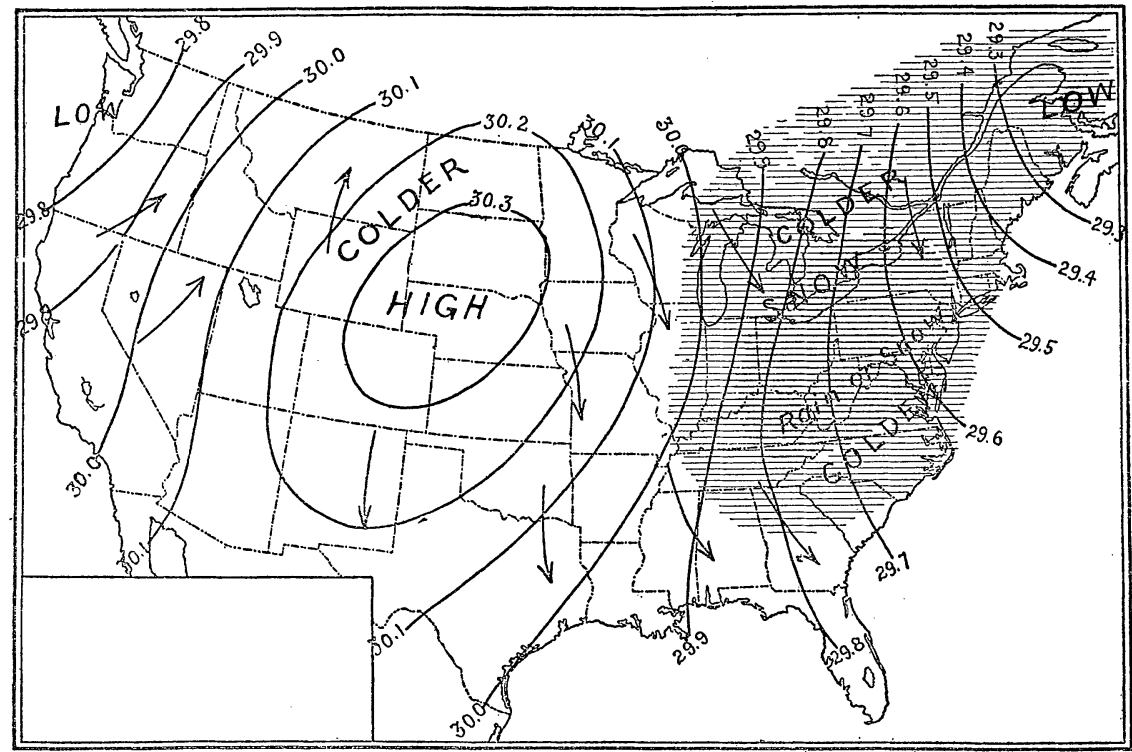

FIG. 12.-North Pacific Type (southern circuit), fifth day. 
northeast, the tendency is to extend the area of general precipitation over the southern and southwestern Gulf States, as well as over the more northern sections west of the Mississippi River. A more southerly path also usually means that there will be more rain, or snow, and more cool northerly winds. On the other hand, a more northerly path usually results in less precipitation over the southern states.

From the southwest-from the western Gulf of Mexico and from Texas,--comes a group of cyclones known as the "Southwestern" or "Texas" type, which develop their essential characteristics in that

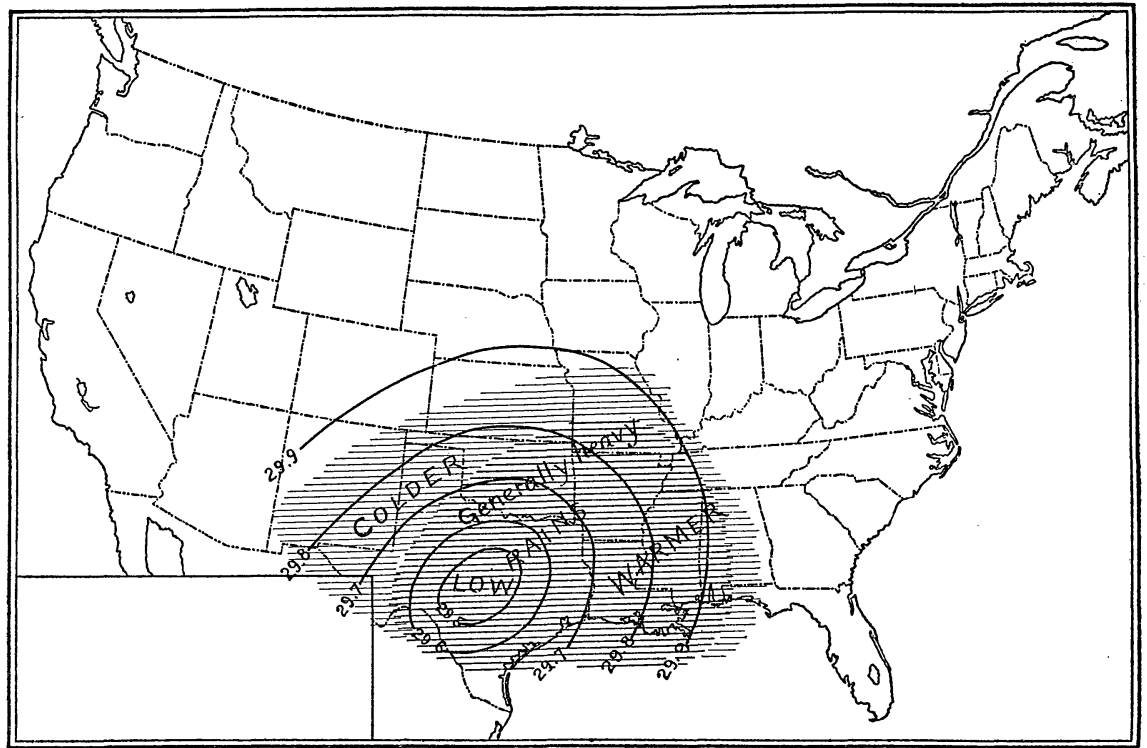

FIG. 13.-Texas or South Western Type, first day.

region. Most of them come from the North Pacific coast, across the interior province; some move in from California; some few come through Mexico. Usually moving northeast across the Mississippi, they reach the vicinity of the Lakes or the Ohio Valley in about one day, and New England or the Gulf of St. Lawrence in about another day. Some take the outside route, along the Atlantic coast, for a part or the whole of their northward journey. The most typical and best-marked storms of the "Southwestern" type come in February and last through March and perhaps into April. Their habit is to increase in intensity and in velocity of progression as they advance northeast. They are preceded and accompanied by a decided rise in temperature and by general and usually heavy rains over the castern United States, east and southeast of their centres, especially over the Gulf and Atlantic Coasts and in the Ohio Valley. When tempera- 


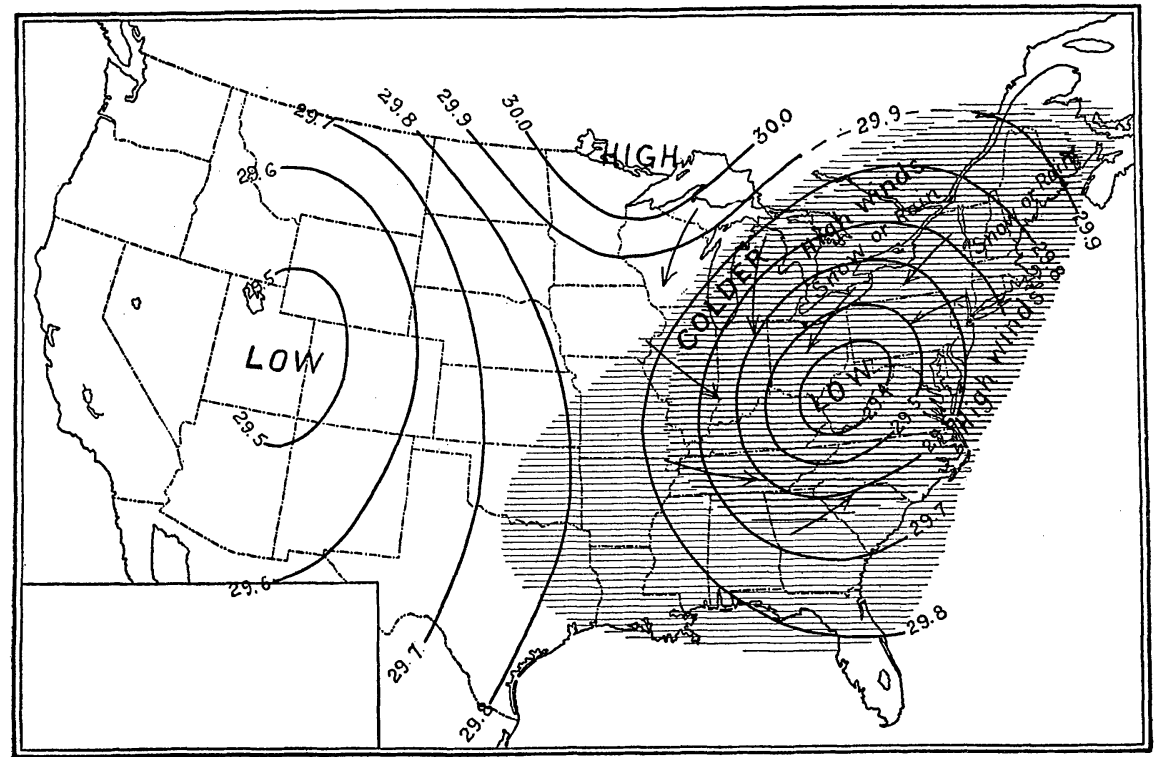

Fig. 14.-Texas or South Western Type, second day.

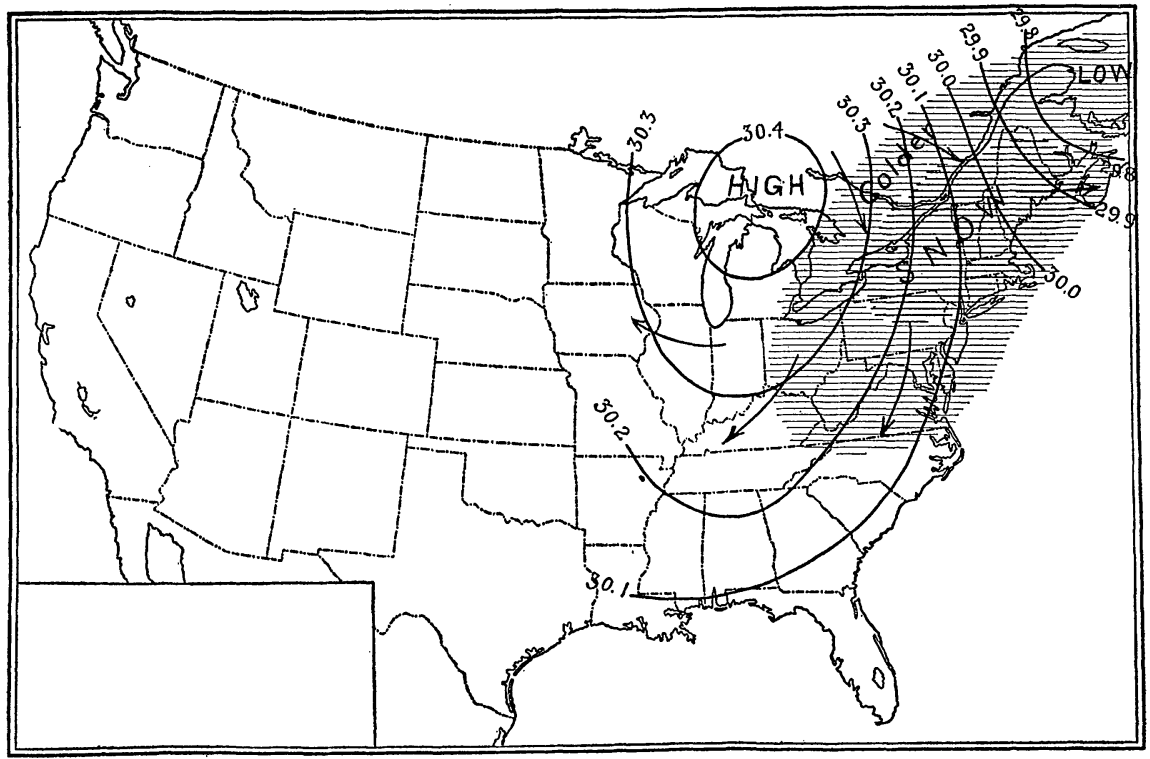

Fig. 15.-Texas or South Western Type, third day. 
tures and other conditions are favorable, heavy snows are frequent to the north and northeast. Our first autumn snowstorm in northeastern sections often comes with the approach of one of these southwestern storms. These storms not only rank as heavy rain-bringers, but also belong, as a whole, among the most severe storms of the eastern United States, with their high winds and their marked temperaturedifferences between front and rear. The extended rain area of a southwestern storm, having already spread over a considerable section of the Gulf States, and even of the Great Plains, may cover the lower Mississippi and Ohio Valleys in the first 24 hours after the development of the low over the western Gulf, and then reach the Atlantic Coast and the New England States in the second 24 hours. Over the Great Lakes and the north Atlantic coast storms of this group begin with northeasterly winds, generally increasing to high velocities, and backing to the northwest. Gales dangerous to navigation over northeastern sections are frequent under these conditions, and storm warnings are usual at such times. A high from the northern plateau, or eastern Rocky Mountain slope, usually follows the storm, drifting first south and then northeast, acting with the low to produce the fall in temperature. A marked high on the north Atlantic coast sometimes blocks the storm, and changes its path. Figs 13 to 15 illustrate weather conditions which are fairly characteristic of southwestern storms as these disturbances progress from the western Gulf of Mexico to the Gulf of St. Lawrence.

Storms of the "Colorado" type begin their weather controls in the eastern United States by causing unsettled weather with precipitation, which may be in the form of general rains or snows, or of scattering showers, or thunderstorms (in the warmer months), over a considerable area between the Mississippi River and the Rocky Mountains. To the north of the centre rain or snow falls with northerly winds. Moving eastward toward the Lakes, these storms usually increase in intensity; their precipitation area advances to the Atlantic coast; they are preceded by rising and followed by falling temperatures. Such a storm when over the Lakes may give general rains over the entire area east of the Mississippi, with snow in the north, gales and storm warnings. Often, however, while the rains or snows may be fairly general over the northern half of the country east of the Rocky Mountains, the precipitation area does not extend into the southern tier of States. There the effect of the storm may be merely to raise the temperatures in front and to cause fair to cloudy weather, followed by clearing and cooler in the rear (Figs. 16 to 18).

Storms moving northeast along the Atlantic seaboard, whether coming from the Gulf of Mexico, or first appearing on our weather maps off the middle or south Atlantic coast, are popularly known as " coast 


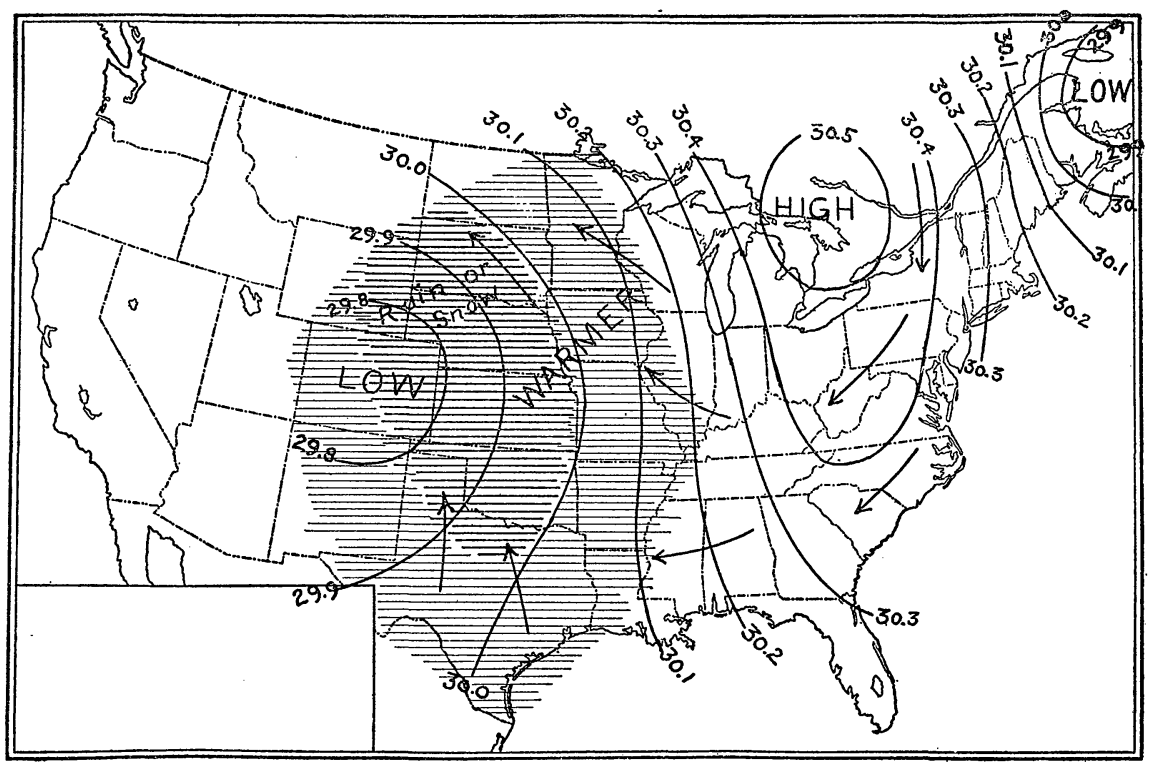

FIG. 16.-Colorado Type, first day.

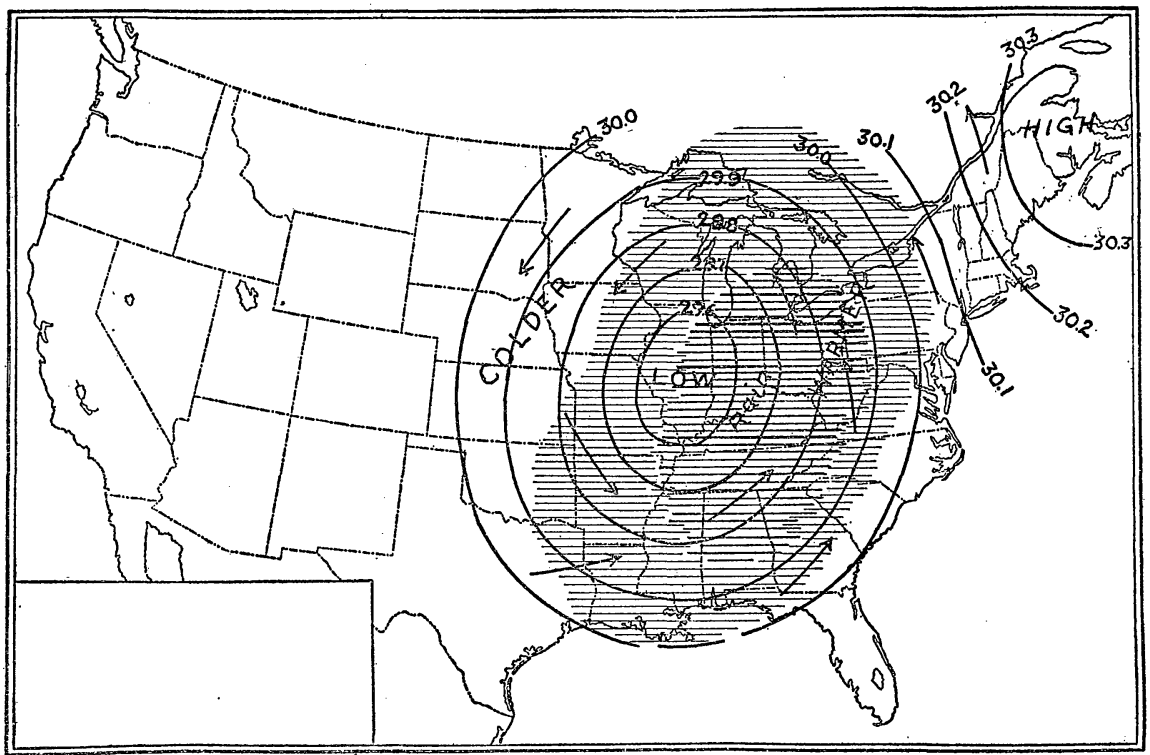

FIG. 17.-Colorado Type, second day. 
storms." While not, as a rule, causing stormy weather over a large part of the mainland, these coast storms are often severe, bringing heavy rains over the eastern Gulf and south Atlantic States and (in winter) heavy snows over northeastern sections, with easterly changing to westerly gales at sea and along the coast. When snow falls, these high winds are a serious handicap to the railroads and to electric car lines because of the heavily drifting snows. Our coast storms are usually followed by rapidly falling temperatures, with high northwesterly winds (Figs. 19 and 20).

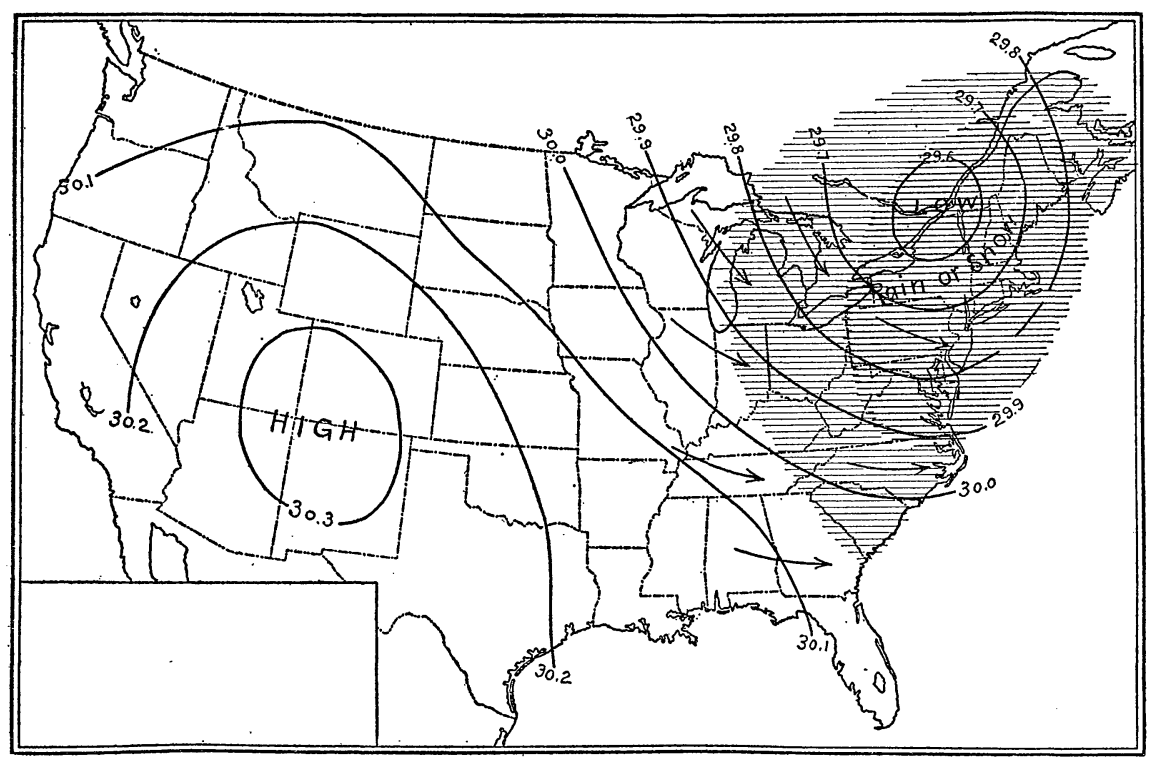

FIG. 18.-Colorado Type, third day.

Although we have been devoting our attention to the weather types which are controlled by cyclones, and by the anticyclones which are most closely associated with them, we should not forget that our weather controls are not always dominated chiefly by low pressure conditions. Not infrequently an immense area of high pressure may cover most of the country, in summer as well as in winter, and clear or fair weather prevail over practically all sections, with more or less marked typical diurnal variations in temperature. In spring and autumn such conditions are often favorable for frost. Fig. 21 illustrates the far-reaching influence of an immense anticyclone central over the northern Great Plains. After the disappearance of the retreating cyclone in the northeast, the anticyclonic control becomes dominant over practically the whole country. 


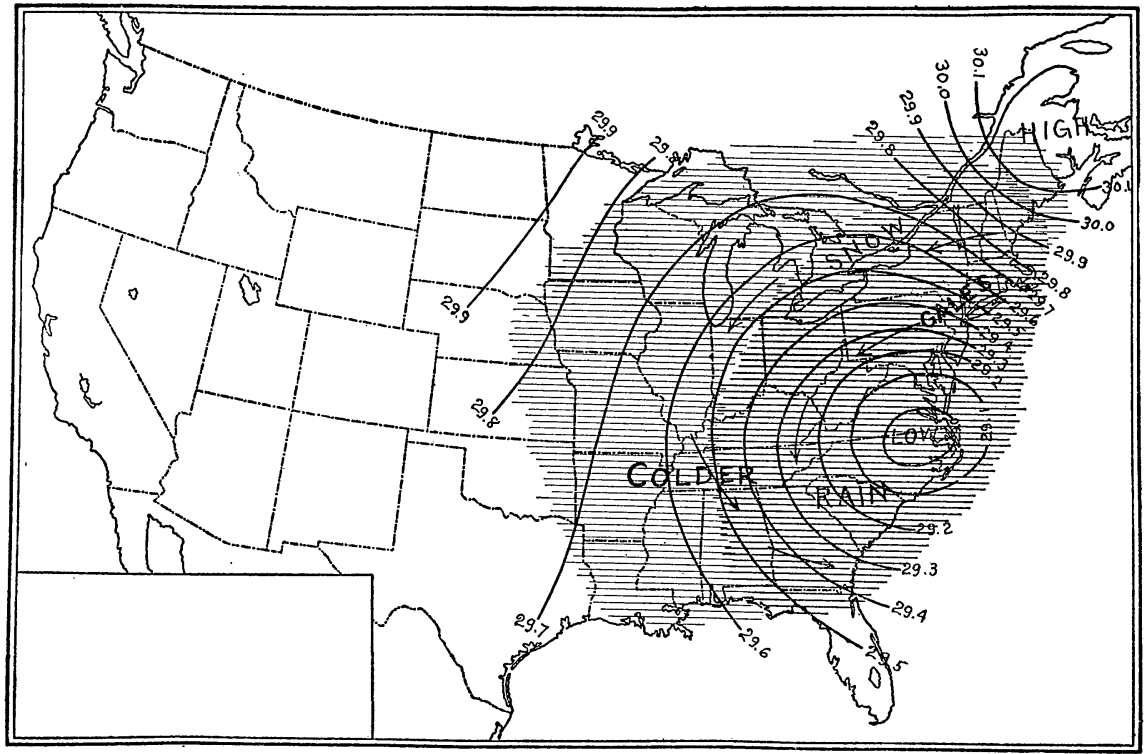

Fig. 19.—Coast Storm, first day.

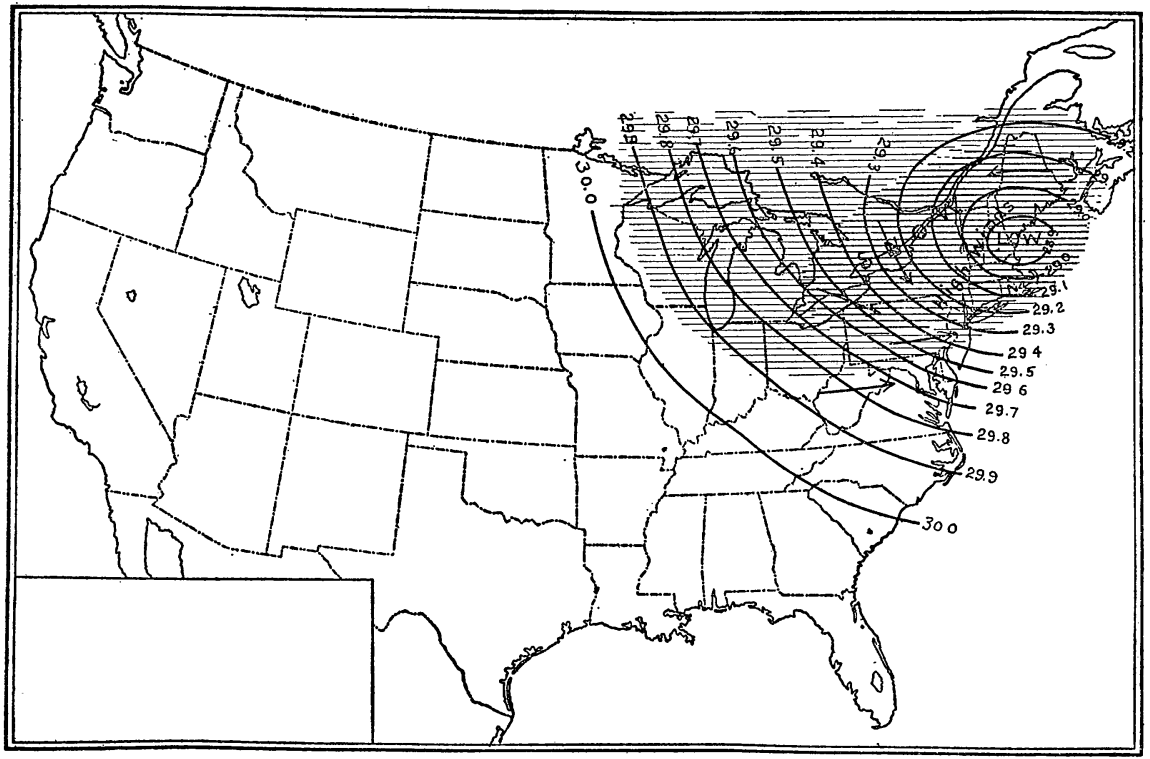

FIG. 20.-Coast Storm, second day. 
Summer Weather Types of the Eastern United States.-Summer weather in the eastern United States is generally peaceful and uneventful. It is frequently marked by periods of stagnation of the lows and highs. A weak summer cyclone, usually without a widespread cloud area, passes along the northern circuit, followed by an area of high pressure which moves off the middle Atlantic coast. On the northward gradients in front of the approaching low is a belt of warm, muggy, southerly winds, which spreads eastward as the low advances. The temperature rises higher each day for several days in succession, reaching maxima which cause great suffering and many deaths, espe-

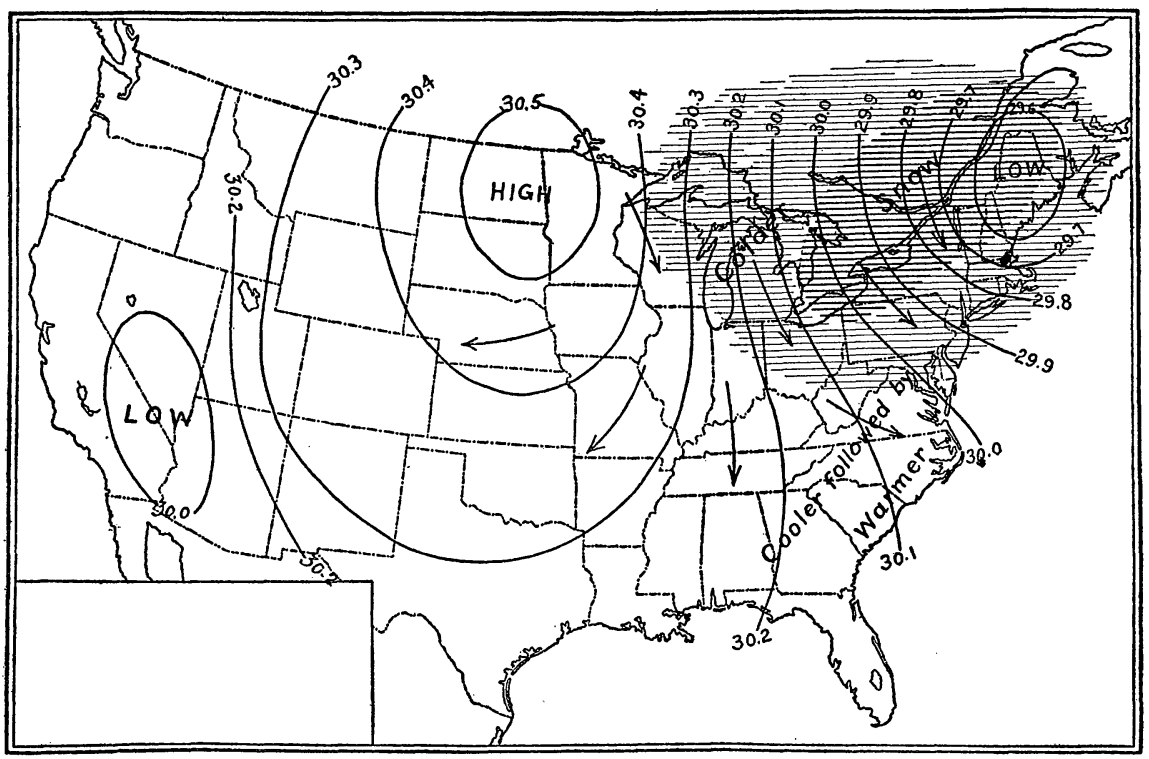

Fig. 2].-Dominant Winter Anticyclone.

cially in our crowded cities. Often these hot spells are cloudless, the sun blazing down with relentless fury undiminished by so much as a single cloud. Thunderstorms, following the increasing growth of cumulus clouds, are common during these hot southerly spells, especially at the time when the winds in the rear of the retreating low shift quickly to northwesterly. Under these latter conditions there follows a welcome fall in temperature in the brisk, cool northwesterly winds. The high advances from the west. The winds soon decrease in velocity. There comes a short spell of clear and cool weather, with marked diurnal variation of temperature, giving pleasantly refreshing nights. Occasional showers may fall on the margins or towards the centre of the high, and soon the approach of another cyclone starts the whole succession of weather types over again. Variations on the general theme occur as the cyclonic and anticyclonic controls differ in 
each case. There are no two series of these weather types exactly alike. That fact adds an interest to weather study which frees it from all trace of monotony.

In summer, most of our rain over the eastern United States falls sporadically, in thunderstorms, which are especially large and well developed from the Mississippi Valley to the Atlantic. While these thunderstorms are usually of short duration, they are often violent, and give heavy rainfalls in a short time. A summer month with heavy rainfall is likely to be a month with numerous and well-marked thunderstorms. It must not be supposed that general storm rains are entirely absent from the eastern United States in summer. Widespread and severe cyclonic storms are rare, but occasional lows, on whichever path they travel, may give general precipitation, especially over the northern states east of the Mississippi River but also extending into the middle tier of states to the south. Such general rains are often most beneficial agents in breaking a long spell of drought over the great wheat and corn belts of the west.

A very characteristic summer weather map shows a well-marked anticyclone over the south Atlantic and eastern Gulf States. This is really a westward extension of the sub-tropical high pressure area of the north Atlantic Ocean. Down the northward gradients of this anticyclone flows a great body of southerly winds, especially when the gradients are reinforced by the presence of a cyclone advancing eastward on the northern circuit across the Lakes and down the St. Lawrence. These conditions give us our most severe summer hot waves over the interior valleys and the eastern districts. The pressure gradients which produce hot waves are thus the reverse of those which bring cold waves. The larger and better developed the anticvclone, and the longer it remains stationary, the more severe and the longer lived is the hot wave; the less the chance of local showers. The weaker the anticyclone, and the more its control is overcome by occasional low pressure areas from the west, the more frequent the interruption of the hot wave by thundershowers and cooler westerly winds.

Spring Weather Types of the Eastern United States.-Spring weather types are, as has been noted, transitional between winter and summer. Thus, in late winter or early spring a pressure distribution of the hot wave type, just described, is a clear indication of the coming of warm-season conditions. Occasional cyclones from the south, with chilling northeast winds and cold rains or snows in eastern sections, are unpleasant reminders that winter has not wholly lost its grip. Especially severe are such storms when the southern low unites with a low coming east on the northern circuit, the two 
joining somewhere on the northern Atlantic coast, and giving high winds and heavy precipitation, which may be snow or rain according to the temperatures. If such a storm "hangs fire" on the coast, as happened in the case of the famous "March blizzard" of 1888, the resulting precipitation is unusually heavy. Winds from the cold continental interior bring wintry temperatures at intervals in the midst of warm, spring-like weather types.

Spring advances from the far southwest, gradually spreading north and east, and starting into activity all the varied agricultural and outdoor occupations which have waited through the turbulent winter months of our northern States for the return of summer. It is in the northeast that winter lingers longest, about the cold waters of the Great Lakes, and in northern New England. Our spring frosts, coming under clear anticyclonic skies, are so emphatic a type that there is little difficulty in forecasting their occurrence from the daily weather map. Destructive spring frosts obviously suggest weakening winter controls, but April showers, often really nothing but embryo thunderstorms, presage summer.

Autumn. Weather Types of the Eastern United States.-Autumn brings many of the most satisfying days of the whole year-those bright, clear, bracing days, under high pressure control, with their warm noon hours, followed by crisp, even chilly, nights, with frequent autumnal frosts of increasing severity, and the characteristic nocturnal valley and lowland fogs of our colder season. There are few more glorious spells of weather than those which we call our Indian Summer, with their light, balmy southerly breezes blowing northward from an anticyclone over the south Atlantic States; their soft and hazy skies; their touch of summer warmth which they bring back to us after we have already begun to feel the keen bite of winter cold. Real summer spells these are,-and they are the last until the following spring, wedged into the midst of the storms which are then becoming increasingly frequent and severe, and of cool waves which are soon to become cold; and delaying, temporarily at least, the advance of winter.

Our autumn cyclones, most of them following the northern circuit, take on their winter habit of greater violence and of more rapid progression over more southerly latitudes. Not a few of them, however, still bear the summer earmarks of a deficiency of precipitation, but their inflowing winds of increasing velocity, and their extended cloud sheets and general rains, or even snows, make it more and more difficult for the sun to control the temperature. Gales and the number of rainy days increase over the Great Lakes and in northeastern sections, because those districts are near the storm centres, whose control 
does not extend as far southward as is the case later in the season. General cyclonic storms-characteristic of winter-show an increasing control over weather as early as September, and to this fact is probably due the widespread, but mistaken, popular belief in an "equinoctial storm."

The West Indian hurricanes of autumn, although smaller than most of our own storms, are more highly developed and more severe, usually cause violent gales and heavy rains along the Atlantic and Gulf coasts, and are destructive to shipping interests, and even to buildings. Fortunately for interior sections, their influence does not extend far inland. The total annual rainfall at many of the stations

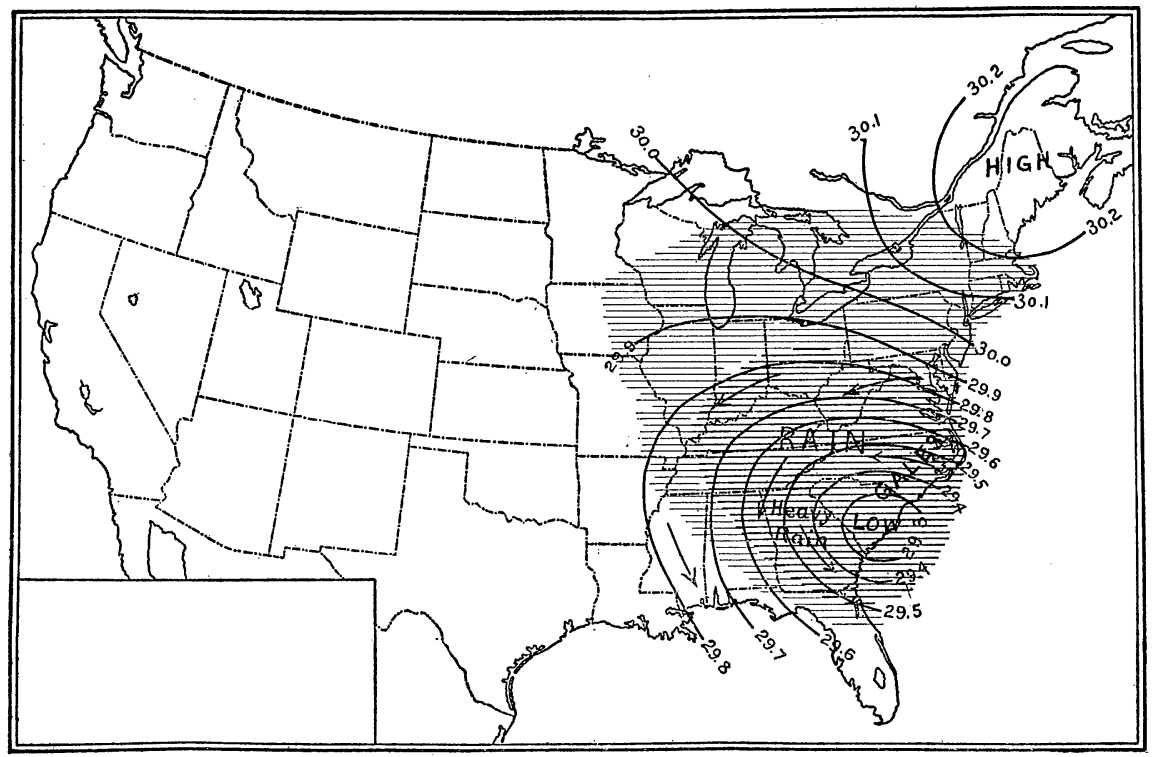

FIg. 22.-West Indian Hurricane, first day.

in these southern coast districts is markedly affected by the occurrence or non-occurrence of tropical hurricanes. When a West Indian hurricane joins, by means of a long trough of low pressure, with a storm from the Great Lakes off the middle or northern Atlantic coast, unusually severe storm conditions are sure to follow, especially along the New England coast. A high, following closely on the rear, is likely to bring rapidly falling temperatures, with snows, in late autumn. In general, however, the temperature-changes accompanying West Indian hurricanes are much less emphatic than those which are characteristic of the winter cyclones which we have been considering, becanse the former occur near the coast and in the warmer months. Figs. 22 to 24 illustrate generalized weather types during the passage of a West Indian hurricane along our eastern seaboard. 


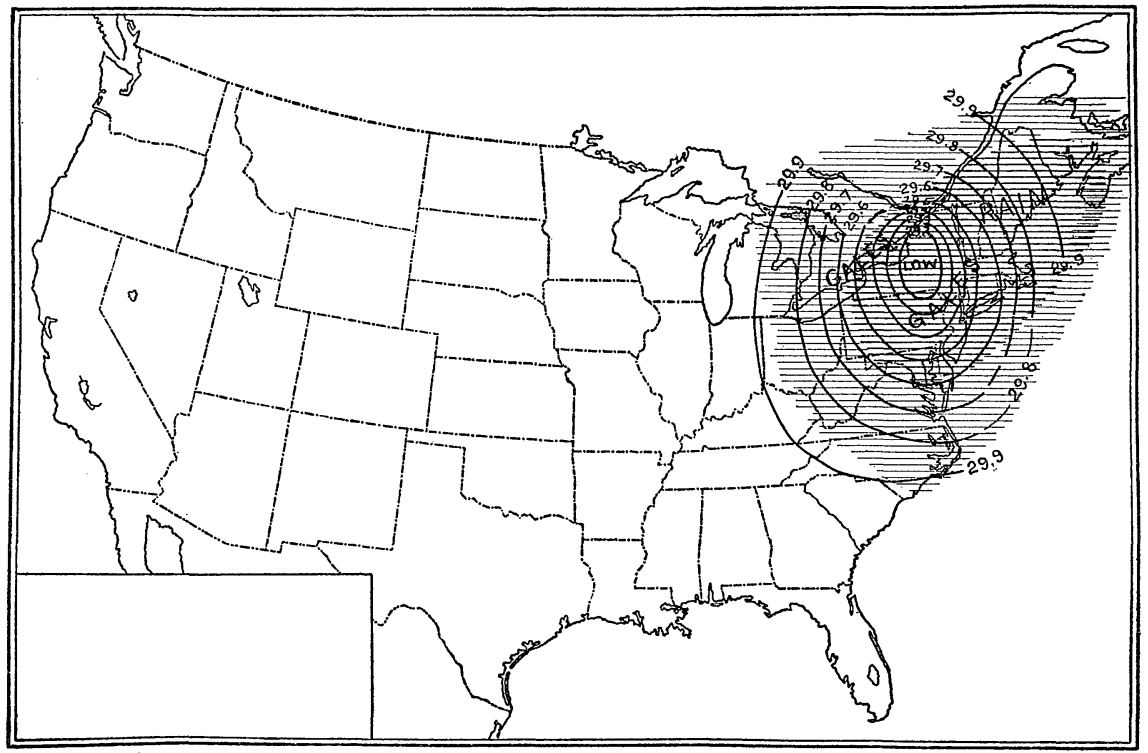

FIG. 23.-West Indian Hurricane, second day.

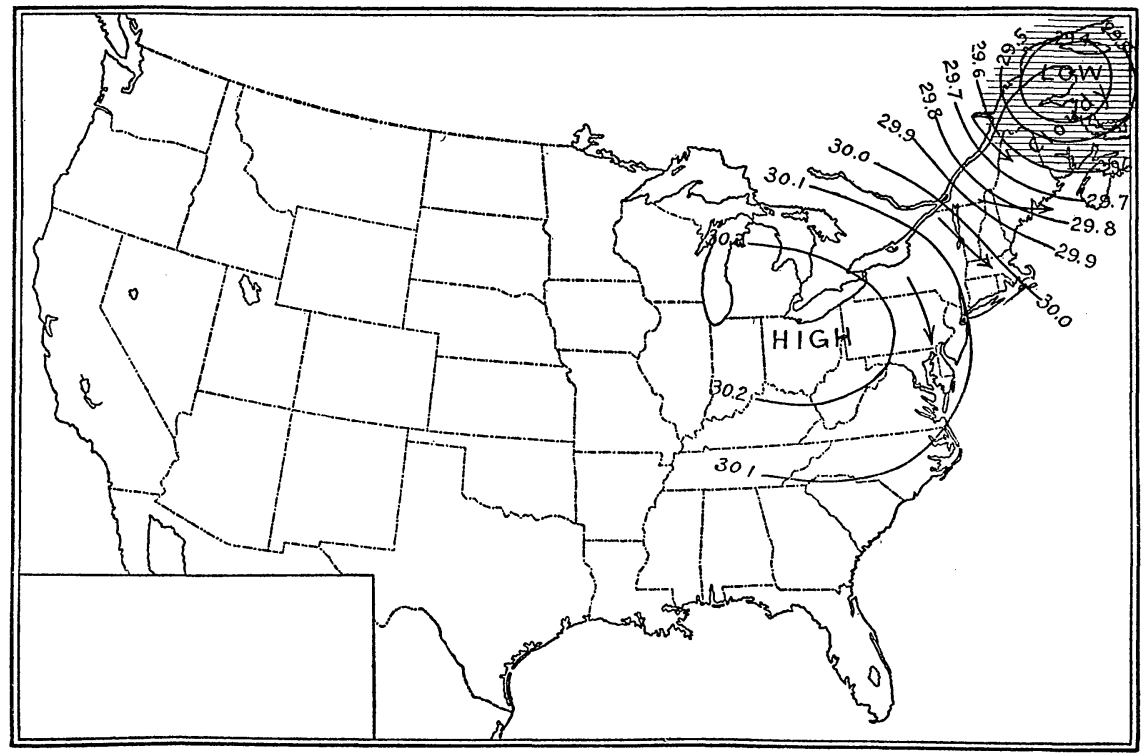

FIG. 24.-West Indian Hurricane, third day. 
Curves Illustrating Weather Types of the Northeastern United States.-The characteristics of some of the more common weather types of the eastern United States may be better appreciated through an examination of a series of curves, selected to illustrate typical conditions of frequent occurrence. The curves here shown were recorded

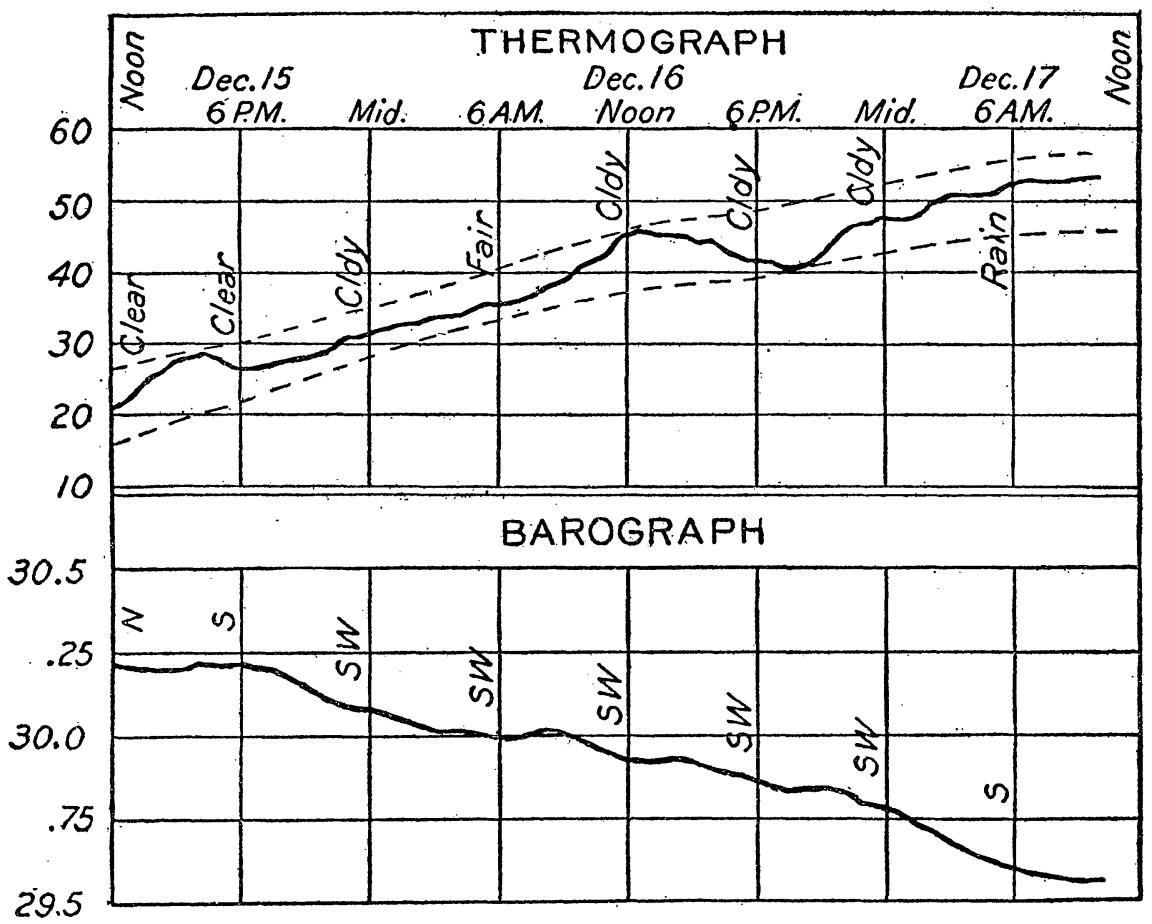

FIG. 25.-An excellent illustration of the cyclonic control of winter temperature changes. With the approach of a winter cyclone warm, damp, cloudy, southerly winds (" sirocco") cause a decided, though gradual, rise of temperature, which is entirely independent of the time of day. The maximum on December 15 comes at midnight; the rise of the temperature belt continues over night of the 15th, through the 16th and into the morning of the 17th, bringing a decided winter thaw which is helped by the warm rain of December 17th. Under such conditions of high temperatures, our heavy winter clothing and our overheated houses are uncomfortable. Warm rains, like those indicated on December 17th, are likely to cause freshets if prolonged, especially when the ground is deeply covered with snow. A slight cooling appears in the early night of the 16th, but the temperature belt as a whole is very narrow. Notice particularly the fact that on December 16 the minimum temperature comes at the first midnight and the maximum at the second midnight, $i$. e., the "diurnal range" is cyclonically controlled.

on the thermograph and the barograph of the Jackson Company, of Nashua, N. H., a representative New England station, and were chosen because New England, as a result of its peculiar position in relation to cyclonic paths, offers unusually favorable opportunities 
for studying cyclonic control of weather and climate. The illustrations which follow are taken from material in the Climatological Laboratory of Harvard University, whose preparation was originally suggested by Professor William Morris Davis. The state of the sky is indicated along the thermograph curves. The wind direction is shown along the barograph curves. The distance between the broken

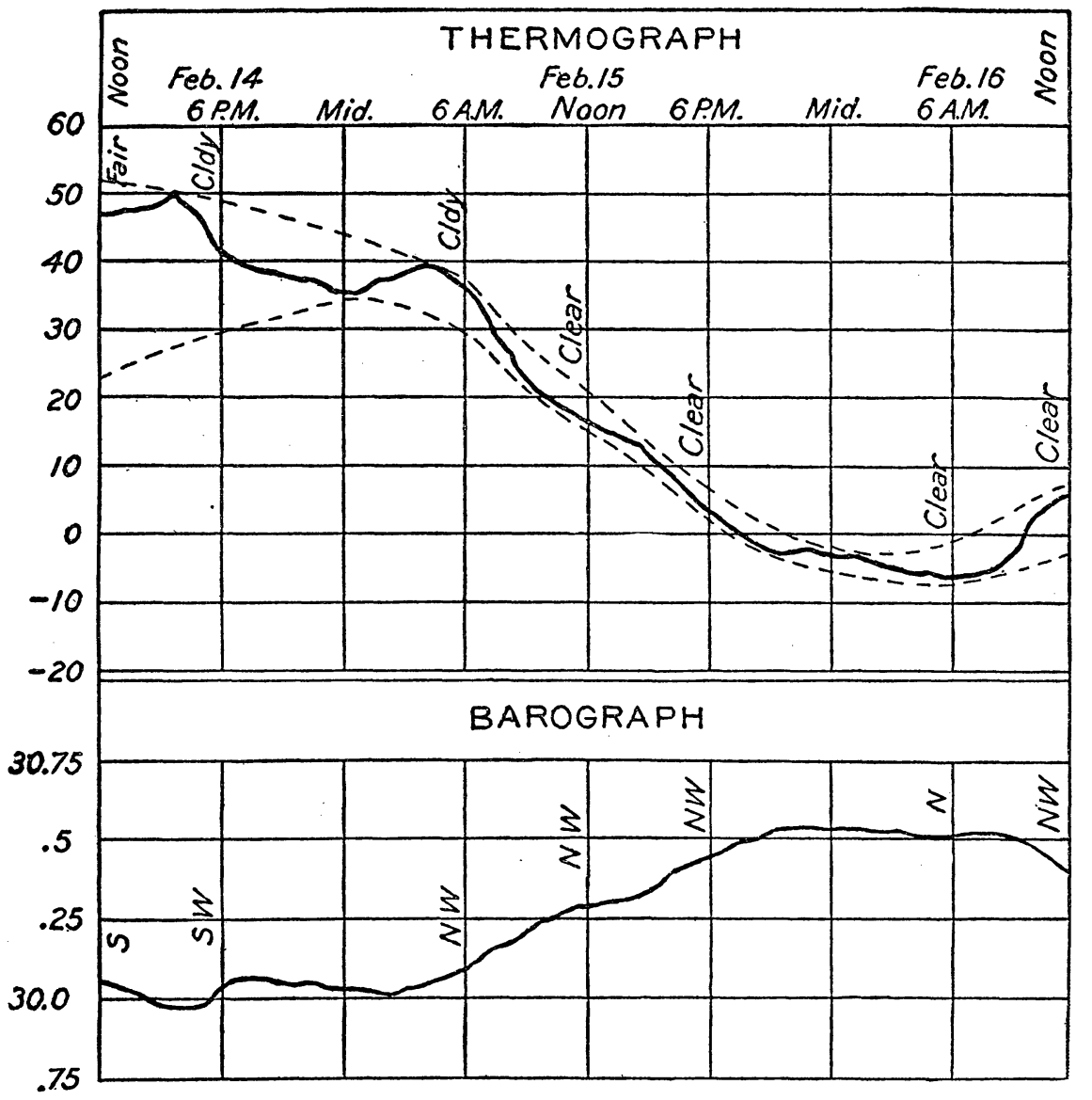

FIG. 26.-February cold wave. A maximum of $50^{\circ}$ is reached under the warm, damp, muggy, southerly winds of a passing winter cyclone (compare Figs. 25 and 27). With a shift of wind into the northwest, a rapid fall of temperature (cold wave) takes place, from the early morning of one day (February 15), through noon, with hardly any trace of diurnal warming, although the sky is clear, to the early morning of the next day, the minimum coming with the highest pressure, and on a clear night (compare Fig. 27). The cyclonic range of temperature is here very clearly brought out in the drop of the temperature belt from one side to the other of the diagram. It is such sudden temperature changes as these that make it hard for many persons who are not in robust health to endure the winters in the eastern United States. The fall in temperature shown above was over $50^{\circ}$ in 36 hours, and during most of that time a strong, biting northwest wind was blowing. 
lines which join the crests and the troughs of the thermograph curves shows the amount of the diurnal range (or change) of temperature. The belt enclosed between these lines (temperature belt) rises and falls with the cyclonic or anticyclonic control of the temperature. Although pressure is not an element of importance in climatology, the barograph curve, when employed in such diagrams as these, is a great help in showing the extent and duration of the successive cyclonic and anticyclonic controls. Such diagrams offer abundant and varied exercises

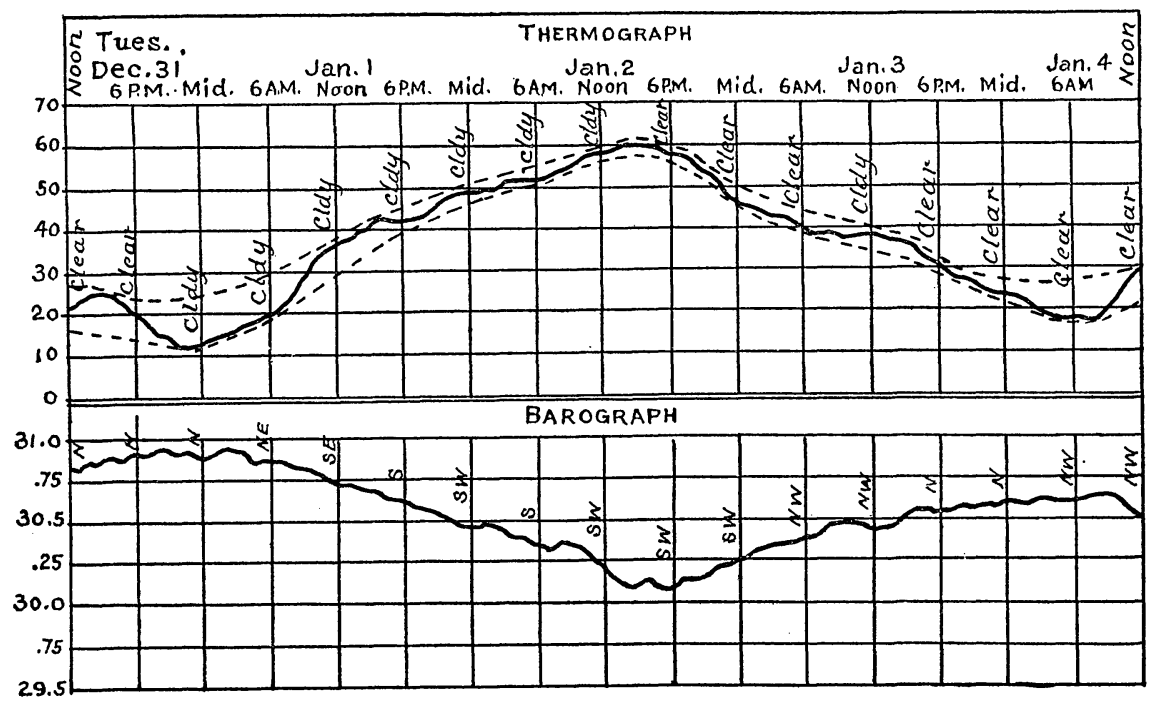

Fig. 27.-A good example of typical winter temperature controls. A marked maximum of about $60^{\circ}$ under the control of the warm southwest winds in association with a winter cyclone, with cloudy weather, comes at the time of lowest pressure (compare Figs. 25 and 26). The two minima come at the crests of the two high pressure areas. On January 1 the minimum is at the initial midnight; the maximum is at the final midnight; the "diurnal range" is wholly cyclonic. On January 3 the maximum is at the initial midnight and the minimum at the final midnight; the opposite condition, but again the range is cyclonic. The temperature belt rises and falls as the cyclone or anticyclone may determine. A glance at the thermograph curve on January 1 and 2 shows how completely the diurnal control has disappeared. The cyclonic rise of temperature on January 1 begins as the northerly and preceding northwesterly winds weaken.

for discussion in laboratory work, and give a clearer and more accurate view of the complexity of our climates than can be obtained from any of the normal climatic tables. If a series of similar curves were provided for different stations in other parts of the United States, the teaching of our local climatology would be greatly simplified, stimulated and improved. Each weather type has its own special and characteristic economic and human responses. An understanding of these types is often of great help in making individual weather forecasts, 
for two or three days ahead, and in preparing oneself to guard against the unfavorable effects of the different types, as well as to profit by the favorable effects. As any such type curves remain type curves, whenever they are recorded, the year of occurrence obviously matters little. The curves are arranged by seasons, and the most important facts are noted in the text accompanying each figure.

Each Section has its own Weather Types.-The accompanying curves relate to one station only, in New England, but the weather types which they illustrate are found, more or less modified, over most of the eastern United States. In the southern States, with increasing distance from the most frequented cyclonic paths, the cyclonic control

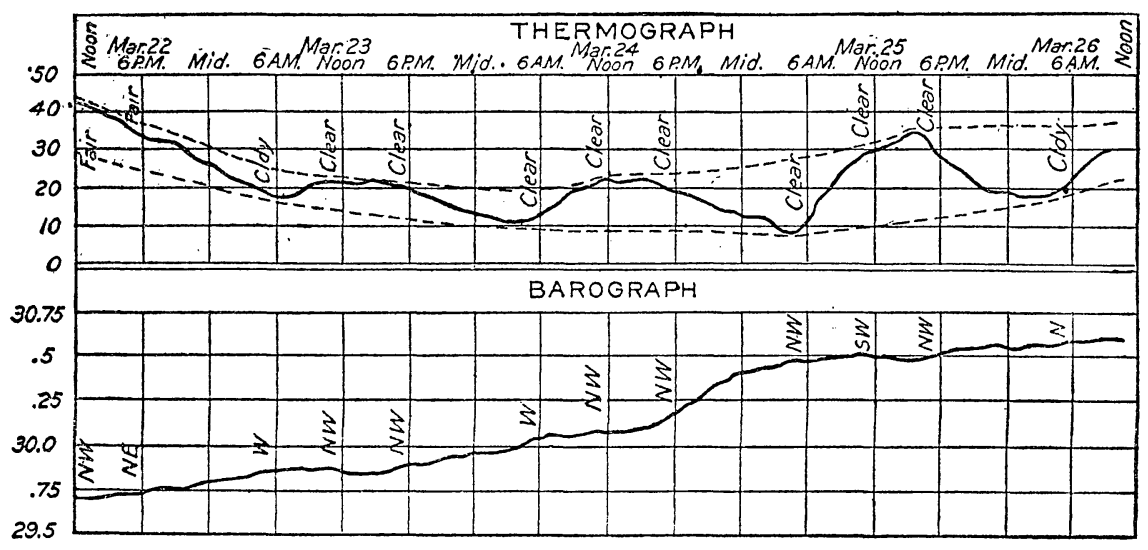

FIG. 28.-Under the active, cool, and dry northwest winds in the rear of a March cyclone the temperature belt is narrow (small diurnal range), because the imported cold cannot be overcome by the noon warming produced by the sun. With the approach of the centre of the high, and with light variable winds, the diurnal range increases; the temperature belt therefore widens; the axis of the belt as a whole rises, and the cold becomes less severe. On March 24 and 25 the warming begins before the highest pressure arrives: a sign of spring.

is naturally weaker; the diurnal phenomena are more marked and more characteristic, even in winter; the changes in winds and temperature are rather less sudden, less frequent, less violent. Thus, e.g., in winter, during the passage of a well-developed cyclone along the northern circuit, the southern states may have all their winds from a southerly direction with but little cyclonic control of temperature, while the more northern states have a sudden shift from southerly to northwesterly winds, with a cold wave. Again, the clond and rain areas of cyclones crossing the northern tier of states often do not extend as far as our southern stations. The latter therefore have clear or fair weather, or perhaps a brief shower, while farther north there may be heavy and long continued rains. In winter it very 
frequently happens that snow falls in the north, while the higher temperatures of the lower latitudes bring rain instead of snow. The chilling northeast winds felt on the north Atlantic coast when a cyclone is approaching from the south are not experienced far inland, or far south. Again, in summer, it is likely that the northern tier of States will enjoy the cool waves which come on the rear of our weak summer cyclones, while farther south there is no break in the heat brought

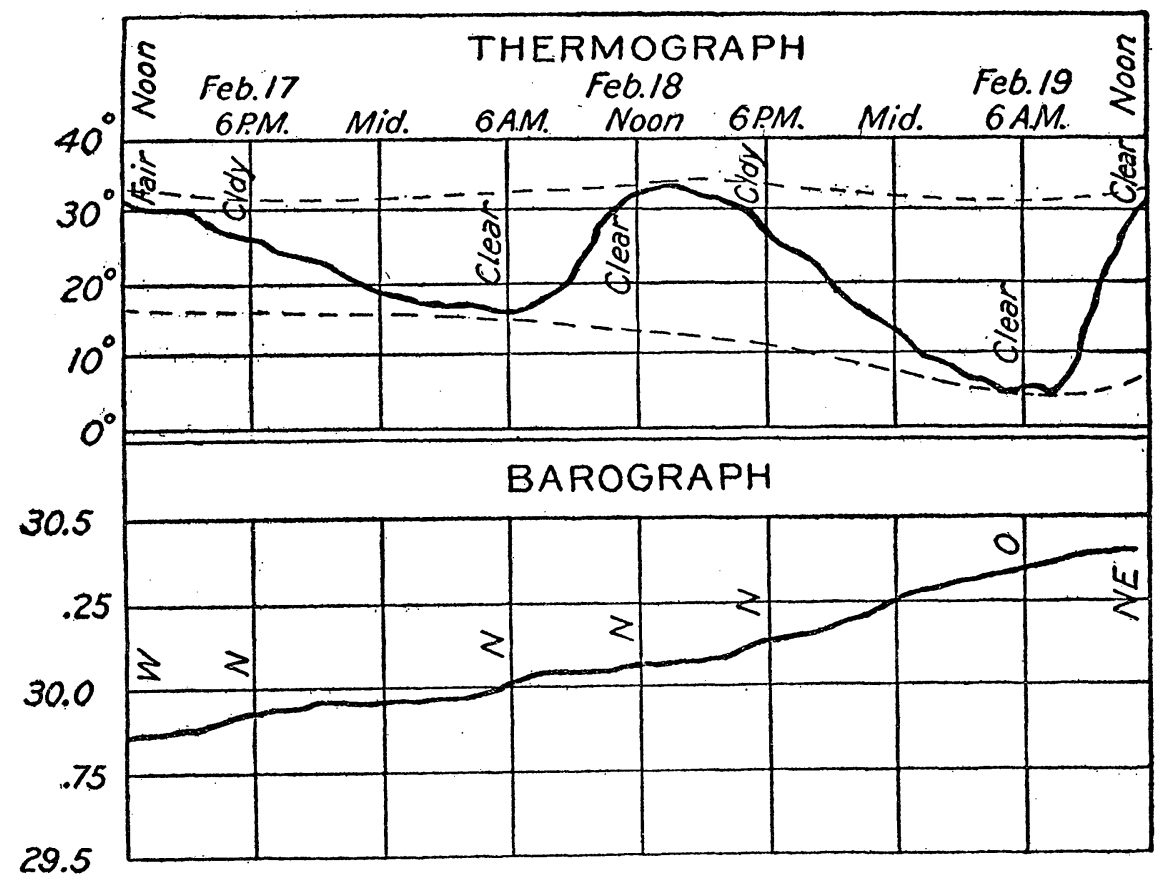

FIG. 29.-Under the light winds of a winter anticyclone we find a moderate winter noon temperature (February 18), the result of a fairly well-marked diurnal range (for winter), and a long, cold night, under clear skies and with no wind. Under such conditions our most marked inversions of temperature occur, the valleys and lowlands having the lowest thermometer readings, while adjacent hill-tops or slopes may have distinctly moderate temperatures. The contrast between the noon temperature (over $30^{\circ}$ ), and the early morning temperature $\left(5^{\circ}\right.$ ) emphasizes the general character of such a winter anticyclonic day, with its agreeable noon and early afternoon, and its chilly night. Notice the widening of the temperature belt toward the centre of the anticyclone.

by the southerly winds. Modifications such as those here suggested, and many others also, result from differences of latitude; of topography; of exposure to winds from the ocean, or the Gulf, or the Great Lakes; of altitude, and from numerous other controls. Each district has its own varieties of weather types. It is sufficient, for our present purpose, to illustrate some of the more important general types as 
these occur in New England. The almost endless series of modifications as they occur in other sections of the country we cannot undertake to discuss further. ${ }^{10}$

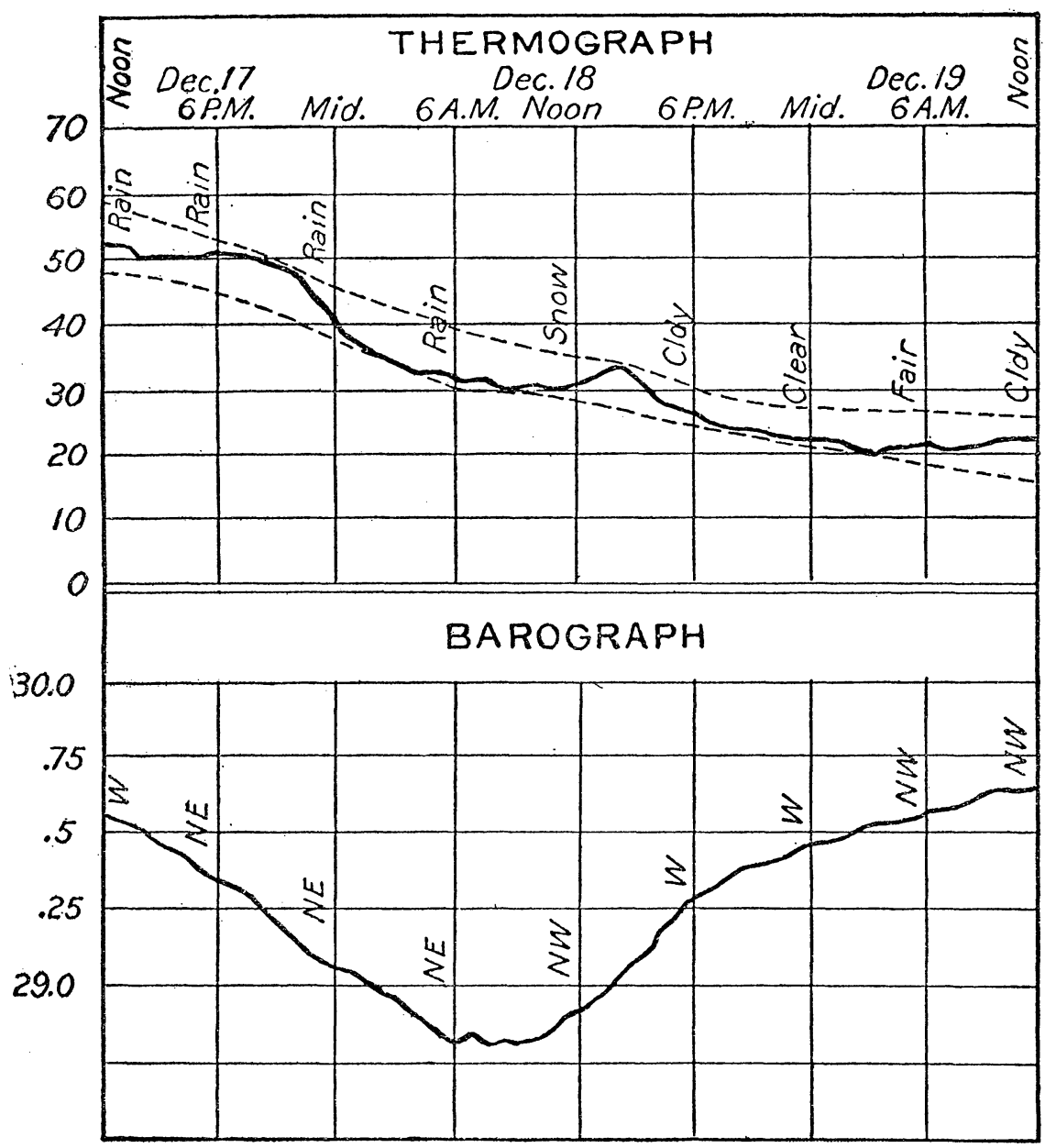

FIG. 30.-A marked fall in temperature under the chilly northeast winds before the passage of a well-developed winter cyclone, with an almost steady fall through noon (December 18) as the result of the imported cold in the westerly winds on the rear of the cyclone. On December 18 the maximum temperature came at the first midnight and the minimum at the second midnight-a striking example of the completeness of the cyclonic control. On December 18, the rain changed to snow as the temperature fell to $30^{\circ}$.

${ }^{10}$ Professor A. J. Henry has given some very instructive curves to illustrate the effect of a difference of latitude upon the weather conditions at five stations situated on the same meridian. (Bulletin Q, U. S. Weather Bureau, 1906, Figs. 1-3, pp. 16-18.) Professor W. M. Davis has presented an excellent description of New England weather types in Annals Harvard College Observatory, Vol. XXI, Part II, 1890, pp. 116-137. 
Regional and Sfasonal Weather Types of the Western United States. ${ }^{11}$-Winter Weather Types of the Pacific Coast.Turning now to the western United States, we find the winter and summer types on the Pacific slope as strongly contrasted as, although differing considerably from, those in the East. ${ }^{12}$ All winter long a procession of storm areas keeps moving eastward across the northern Pacific slope, generally following the international boundary fairly closely to beyond the Rocky Mountains, and continuing thence on the usual paths. Temperatures about normal; mild southerly winds; rains over Washington and Oregon; cloudy weather and showers perhaps extending into California as far as San Francisco, or beyond: these are the usual conditions when a winter storm is over Washington

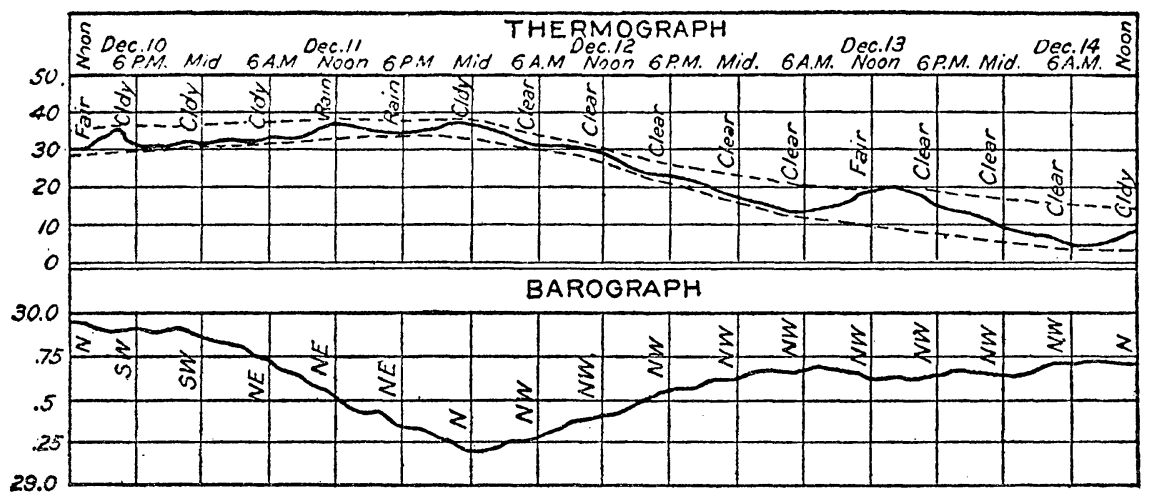

FIG. 31.-In this curve we have only a moderate cyclonic range of temperature, because the cyclonic centre passed to the south of the station, and thus the warm southerly winds (noted in Figs. 25, 26, and 27) were lacking (cf. Fig. 30). The cyclonic clouds and rain resulted, as, usual, in practically extinguishing the diurnal range and thus greatly narrowing the temperature belt. The maximum temperature comes with the minimum pressure, as is usually the case in winter. The cold wave on the rear of the cyclone carries the temperature belt down (compare Figs. 26, 27), the downward slope being but slightly interrupted by a weak diurnal maximum in the afternoon of December 13. On December 11 the chilly northeast winds gave a disagreeable spell of cold, rainy weather.

or Oregon. ${ }^{13}$ With steep gradients, southerly gales occur along the coast from Cape Mendocino to Vancouver Island, and brisk south-

${ }^{11}$ The writer is indebted for helpful criticisms on these sections to Messis. E. A. Beals, F. H. Brandenburg, Ford A. Carpenter, Alexander G. McAdie, and William G. Reed.

${ }^{12}$ B. S. Pague and S. M. Blandford: "Weather Forecasting and Weather Types on the North Pacific Slope." Portland, Oregon, 1897. W. A. Glassford: "Weather Types on the Pacific Coast," Bull. 5, Cal. Acad. Sci., Aug. 31, 1886. Explanatory and descriptive notes on Portland, Ore., San Francisco and San Diego daily weather maps.

${ }^{13}$ See Fig. 8. 


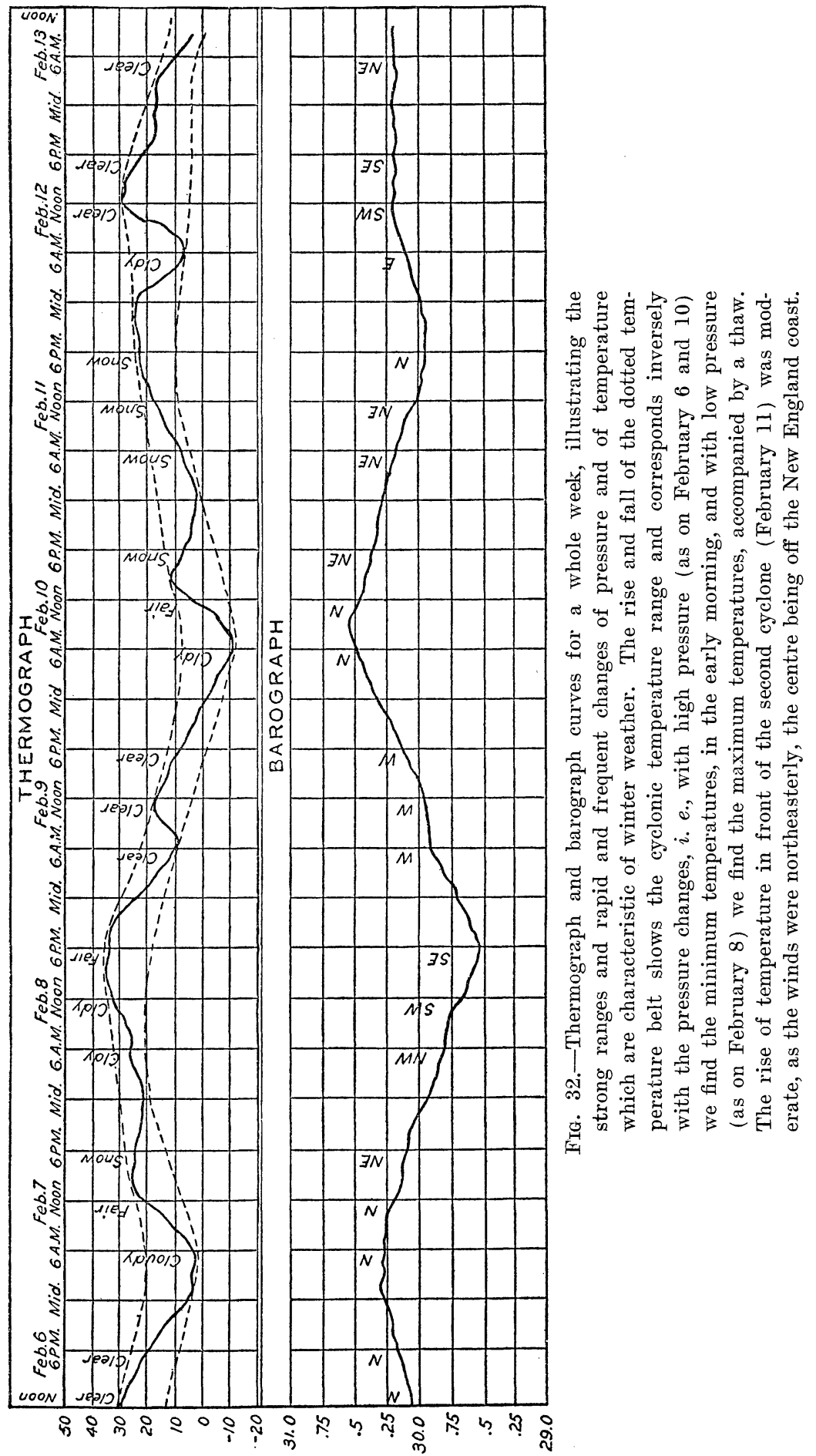


easterly or southerly winds in Oregon and Washington. Rain usually begins with southeasterly winds, continuing as the wind veers to south, southwest and west. When, less frequently, the cyclonic centre moves farther south, northerly winds and clear weather prevail over the northern districts. Winds from the northern quadrants are likely to be fair-weather winds at all seasons. The greater the distance of the storm centre, the less is its control over the weather. At San Diego, for example, perhaps less than one-tenth of the storms which cross the northern section of the Pacific coast have any notable effects. California, therefore, has less rain and cloud than prevail in Washington and Oregon, and southern California has even less rain and

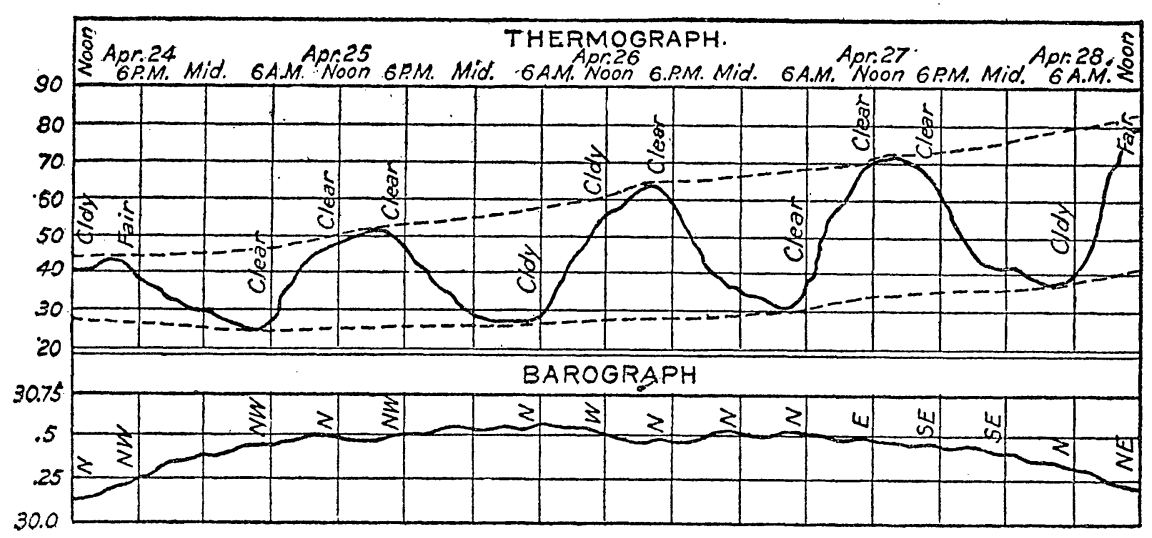

FIG. 33.-Normal diurnal curves, of large range, with a rise in the mean temperature and in the maxima and minima, from day to day under the clear sky of a spring anticyclone. Such conditions give crisp, cool evenings and nights, and bright, warm days. At the beginning of this spell (April 24) the cool wave, with northwesterly winds in front of the approaching anticyclone brought lower temperatures, while the warming increased in the light winds near the centre of the high. The rise in the mean temperature from April 25 to 28 is shown by the rise of the dotted temperature belt. Notice the convex morning, and the concave afternoon curves.

more sunshine than the northern portion of that State. Well-developed low pressure areas are rare in southern California. When they occur, they cause rains. Occasional lows entering the southwestern portion of the State give light rains along the southern coast, and a subsidiary low over southeastern California ("Sonora storm") may cause rains of relatively large amounts, accompanied by considerable wind movement. On Feb. 24 and 25, 1913, with a low over southern California, occurred the heaviest rainfalls on record at Los Angeles.

During the winter, the prevailing movement of anticyclones is from the California coast in the vicinity of Cape Mendocino northward to 


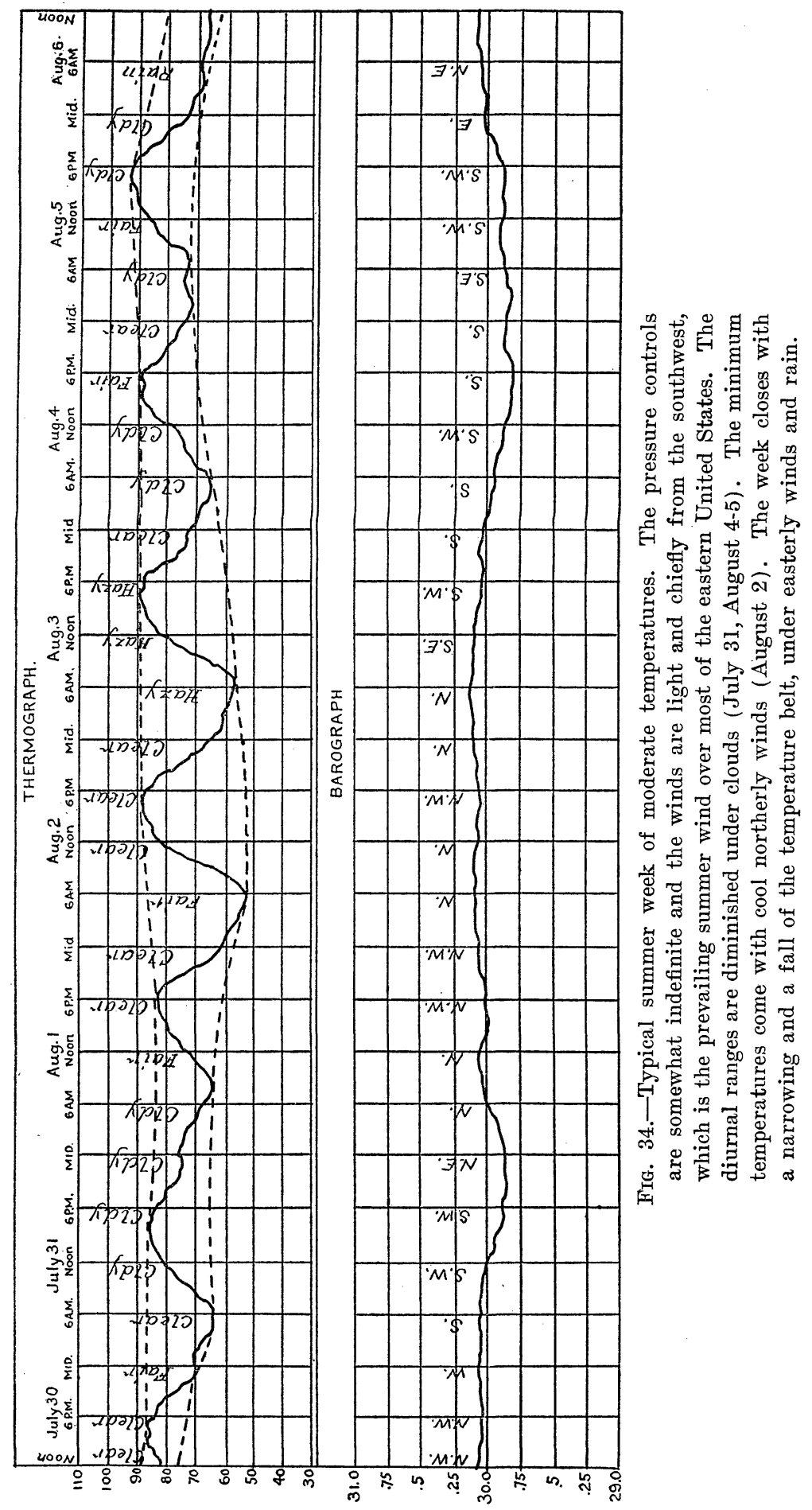


about lat. $45^{\circ} \mathrm{N}$, crossing northern California and southern Oregon to southern Idaho. There they become stationary, or disappear, or move further east. Other anticyclones come from the north of Montana and move southeasterly toward the Mississippi Valley. When the typical winter low is over the northern Pacific coast, there is usually a high central in Utah, or western Colorado. A marked anticyclone, with low temperatures, fairly stationary north of Montana, and spreading westward towards the coast, retards the eastward movement of the north Pacific coast cyclone. The result may be rain of several days' duration west of the Cascades, and perhaps snow, with freezing tem-

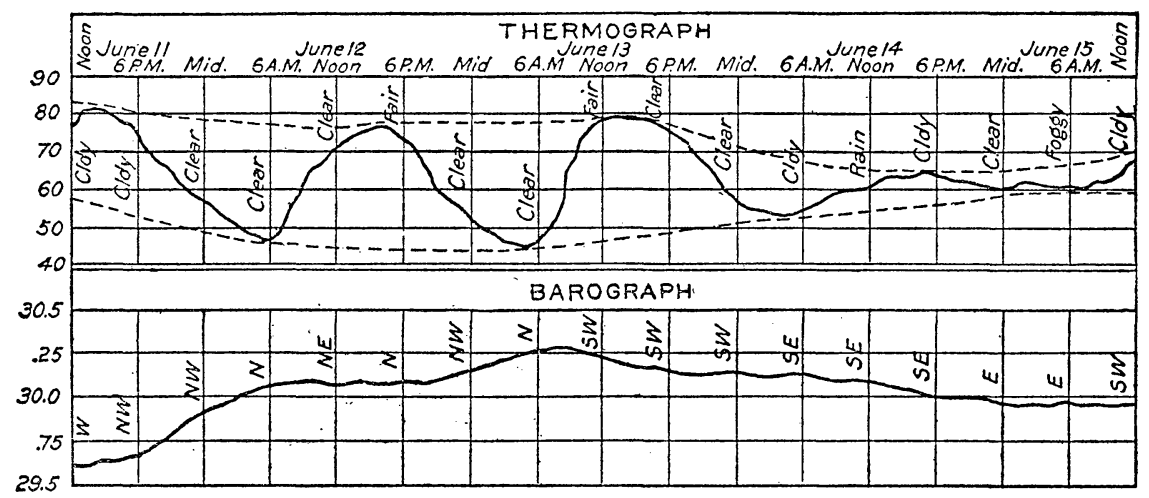

FIg. 35.-Similar conditions to those shown in Fig. 34, but earlier in the season. The maxima are not as high as, and the minima are lower than, those in Fig. 34. On June 14 and 15 there is a marked narrowing of the dotted temperature belt, indicating very small temperature ranges with low maxima, under the ranny and cloudy conditions of these days. The temperature belt is widest under high pressure conditions, the diurnal range being then usually greatest, both in summer and winter (see also Figs. 28, 29, 39), owing to the clear skies with sunshine by day, and the active radiation at night. The temperature belt on June 11 shows a general lowering of the mean temperature in the northwest winds in front of the approaching anticyclone. On June 14, the diurnal maximum is retarded under rain and clouds.

peratures, east of these mountains. If the cyclone is forced southward along the coast, perhaps to the mouth of the Columbia River, and even much further south, there comes a great flow of cold air from the interior, from the north and northeast, which descends the western slopes of the Sierra Nevada and Cascades and comes down into the valleys of Washington, Oregon and California. Heavy snows fall east of the Cascades, as far as Idaho, followed by fair, cold weather over the Pacific coast generally, except on the seaboard. Occasional snows may then fall in western Washington and Oregon, and even on the coast, with northeast winds and low temperatures. With the disappearance of the low to the south, the temperature slowly rises and the snow ceases, but there is no general warming 
until another cyclone arrives, causing strong winds. These northeasterly winds are the coldest winter winds, but they are of relatively infrequent occurrence.

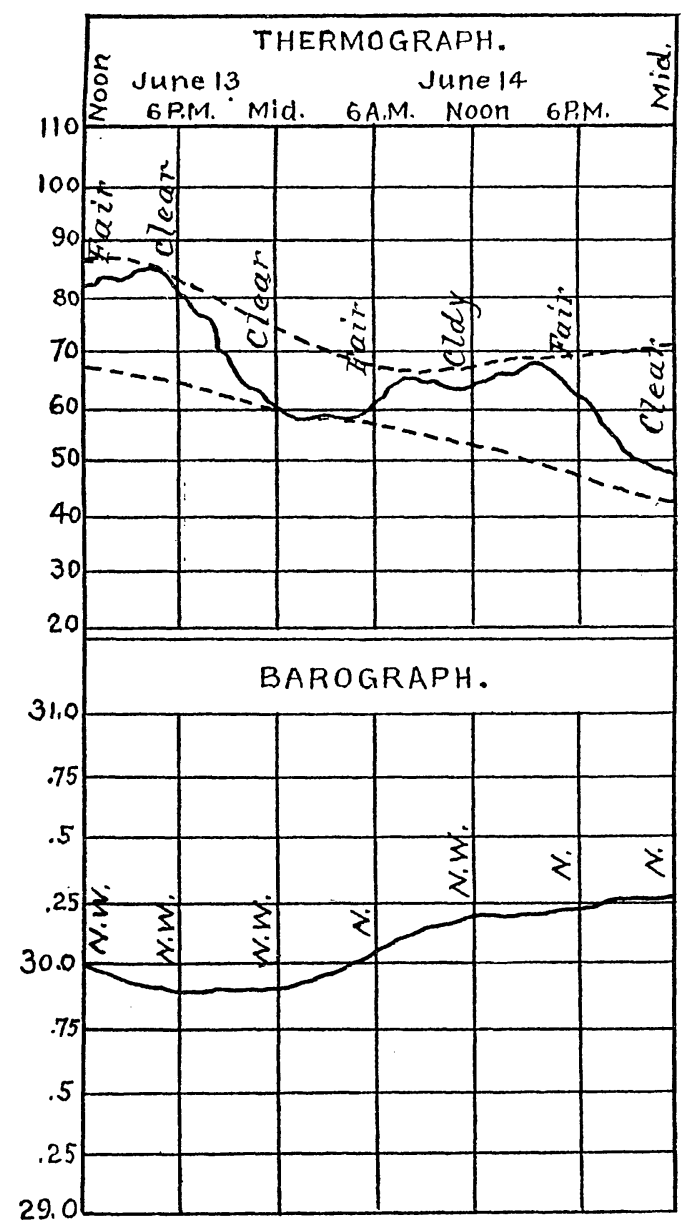

FIG. 36.-Summer cool wave. This temperature curve was recorded during the prevalence of cool northwesterly winds in front of an advancing summer anticyclone. The fall of the temperature belt indicates the general cooling. The cyclonic rise of temperature begins as soon as the northwest winds weaken. The noon maximum is reduced on June 14 by the considerable growth of convectional clouds. Such clouds are a characteristic feature of the fine days which follow our summer rains or thunderstorms. Evaporation is then active under the drying northwest winds, and by noon the sky is often overcast.

Sometimes the low may be forced southeastward over California, bringing general and severe storm conditions in that State, with heavy rains, gales, floods and washouts. An area of high pressure over the northern Pacific coast, or over the Great Basin, with lower pressure 
in southern California, brings prevailingly clear weather and dry air, except for local rains in the far north; warm days, and relatively cool nights. Under such a distribution of pressure, when the gradient is but moderately steep, "northers" occur in the valleys of California, extending southerly.

There are, of course, many subordinate types of high and low development and movement, each of which has its own characteristic control over the weather. The details of these types it is impossible to consider here. The general character of the winter precipitation on the Pacific Coast obviously depends upon the paths followed by the winter storms. These paths are controlled by the surrounding pressure conditions, and probably also by the movements of the upper air currents. The further south the cyclones move, and the more intense they are, the heavier and the more widespread is the rainfall.

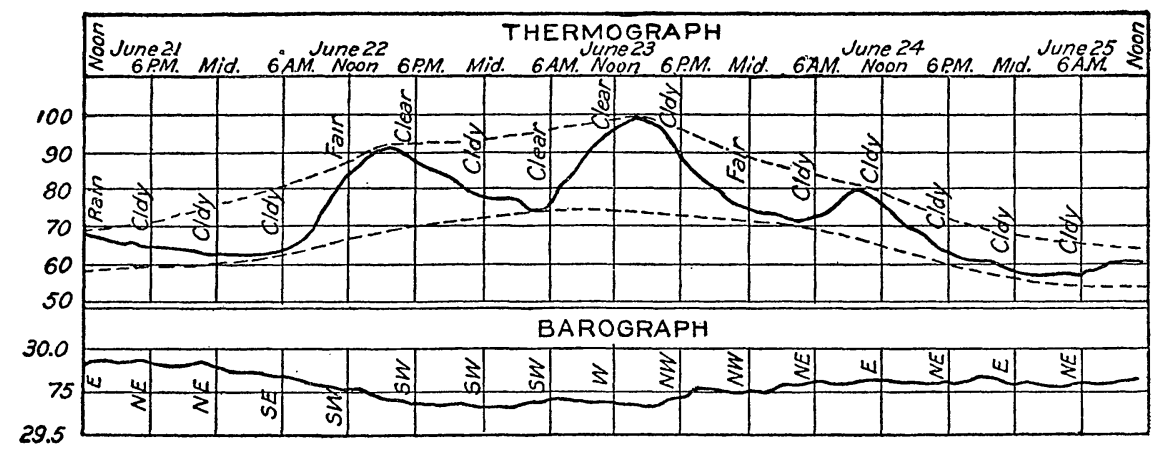

FIG. 37.-Diagram illustrating the contrast between southwesterly and northeasterly winds in New England in summer. Beginning with an even temperature under cloudy skies, easterly winds, and rain, the incoming of sultry southwesterly winds, and fair or clear weather, at once brings a marked diurnal range, with a rise in the temperature belt as a whole under cyclonic control, to a high maximum (June 23). Our highest summer maxima (hot waves) occur under these conditions. Sunstrokes and heat prostrations are then common, and there is much suffering, especially in our large cities. High nocturnal maxima are characteristic of these hot spells. With a shift to northwest winds a general fall in temperature occurs, which is continued under the succeeding east and northeast winds, with small diurnal ranges under cloudy skies, the temperature belt as a whole falling to the right end of the diagram. The low noon maximum on June 25 is due to the cool northeast winds and clouds. Such cool spells afford welcome relief after the high temperatures of a preceding hot wave. The northeast wind is the coolest summer wind on the New England coast.

\section{Summer Weather Types of the Pacific Coast.-From a stormier} winter to a drier, more settled, and fairer summer, the change on our Pacific Slope is in general accord with that which takes place the country over. Northward swings the winter storm belt. Northward moves the cyclonic rain belt. The summer cyclones, travelling east along a higher latitude-about that of Sitka-cannot greatly influ- 

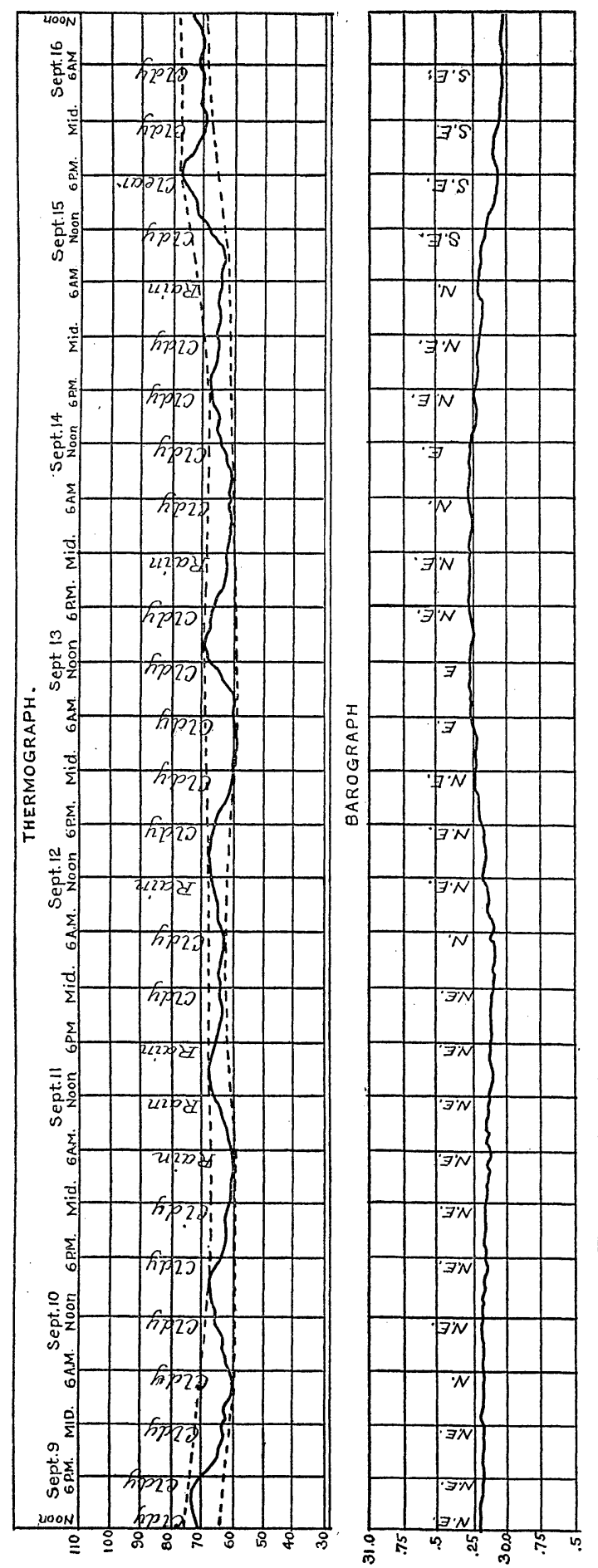

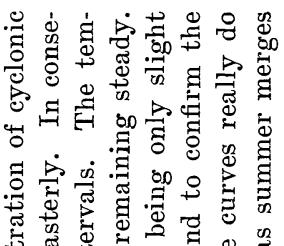

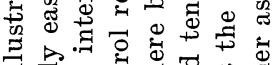

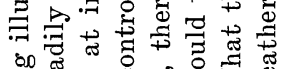
.

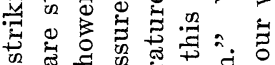

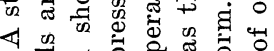

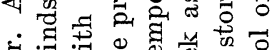

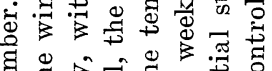

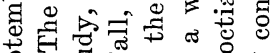

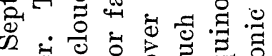

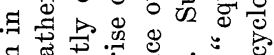
.

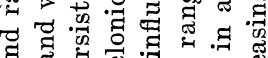
సె 记苛

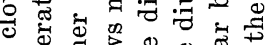

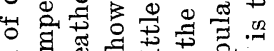

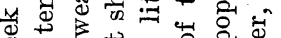

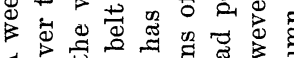
48 के

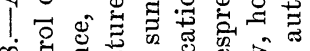

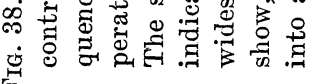

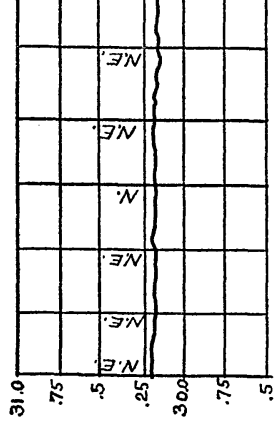
更 
ence Pacific coast weather. They often cause cloudiness without precipitation, but once they have passed beyond the western mountains they are practically negligible, so far as the coast is concerned. The rains diminish as summer approaches. By midsummer, absolute dryness prevails over much of the southern portion of the area. A characteristic of the warmer months is the presence of a more or less

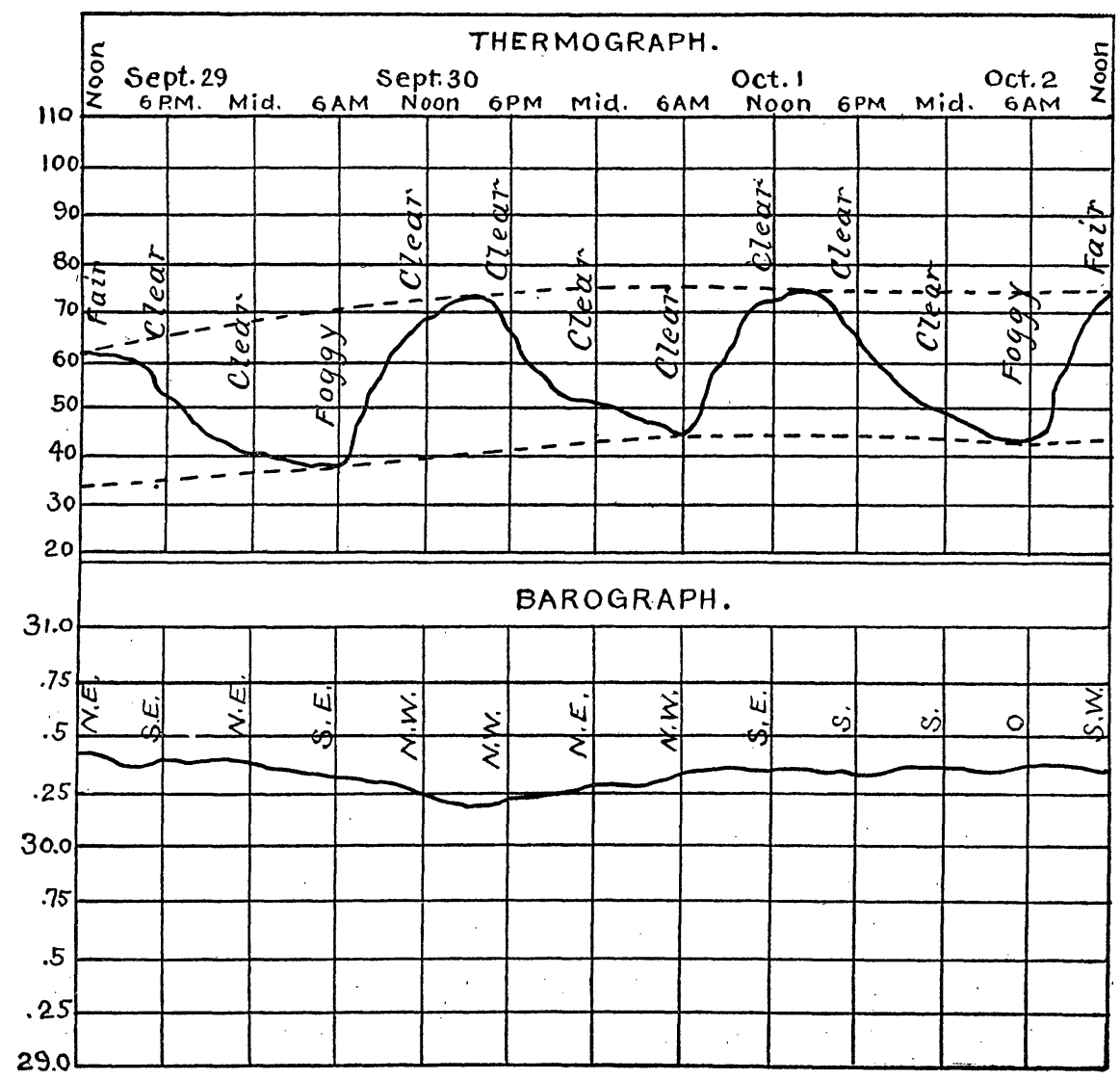

FIG. 39.-Typical fine days in early autumn. Under the light winds and calms of a moderate anticyclone, the diurnal range is well-marked, with warm noons and early afternoons, and crisp, clear nights. The characteristic nocturnal radiation fogs (September 30, October 2) are common in valleys and on lowlands under these conditions. A slightly lower minimum on the night of September 29-30 would have given an autumn frost.

enduring anticyclone over the northern or northwestern Pacific coast, while a permanent low extends from the Gulf of California into the Basin region. (Fig. 42.) Hostile to rainfall this pressure distribution certainly is. A summer dry season is the inevitable result. Settled weather, with cool mornings and nights, and warm afternoons; light and local showers, rather than general rains, and even these showers 
limited to northern sections and to the mountains,- - thus we may characterize, in the briefest possible way, the summer of our Pacific Slope. The prolonged rainy and cloudy spells and lower temperatures of winter give way to pleasanter, although occasionally uncomfortably warm, weather types. Yet the high day temperatures under the strong sunshine of the inland sections are accompanied by low jelative humidities and the "sensible temperatures" are therefore low. There is a general absence of oppressive muggy heat inland, and the coast

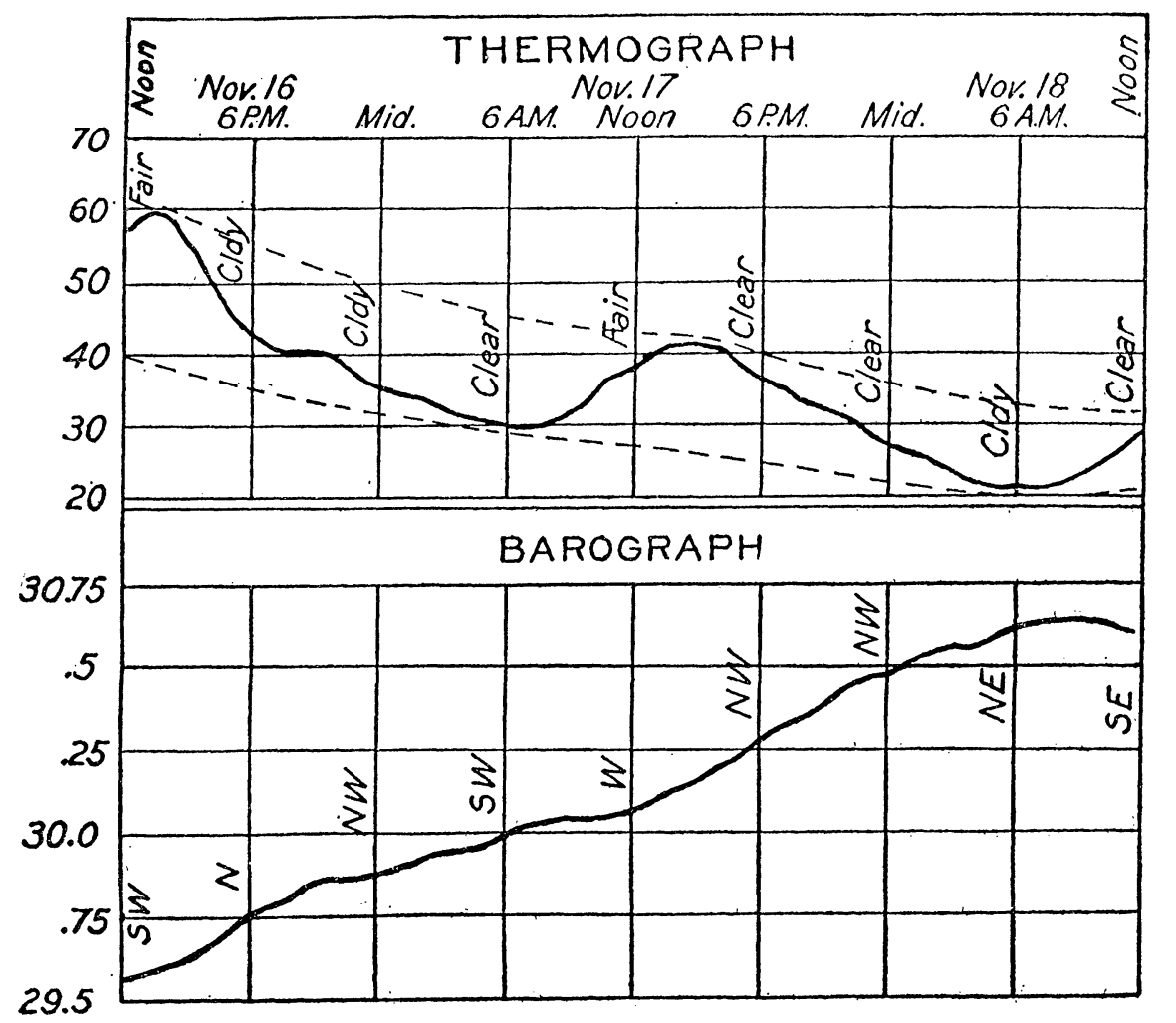

Frg. 40.-An autumn cold wave in front of an approaching anticyclone carries the whole temperature belt down, although the sun is shining, but is unable wholly to extinguish the diurnal range. This illustrates the increasing power of the cyclonic control, which is the great characteristic of winter. The minimum temperature occurs under the maximum pressure, $i$. e., is the result of local nocturnal radiation.

temperatures are indeed distinctly cool. Summer showers in northern sections come from lows passing east of the Rocky Mountains whose weather control extends westward, on their rear, or from a weak cyclone which forms over the great valley and afterwards unites with another low over British Columbia. Thunderstorms, of frequent occurrence in eastern Oregon, eastern Washington and Idaho, are rare in 
the western portions of those States, and in California, except in the higher portions of the Sierra Nevada and of the desert. They occasionally occur in summer in the northwestern, western or northern quadrants of a low passing northeast from the central valleys of California to northern Idaho. Fogs along the coast, while high temperatures prevail in the interior, are a notable summer type.

In summer, the characteristic movement of anticyclones is northward along the coast from Cape Mendocino to Vancouver Island (about

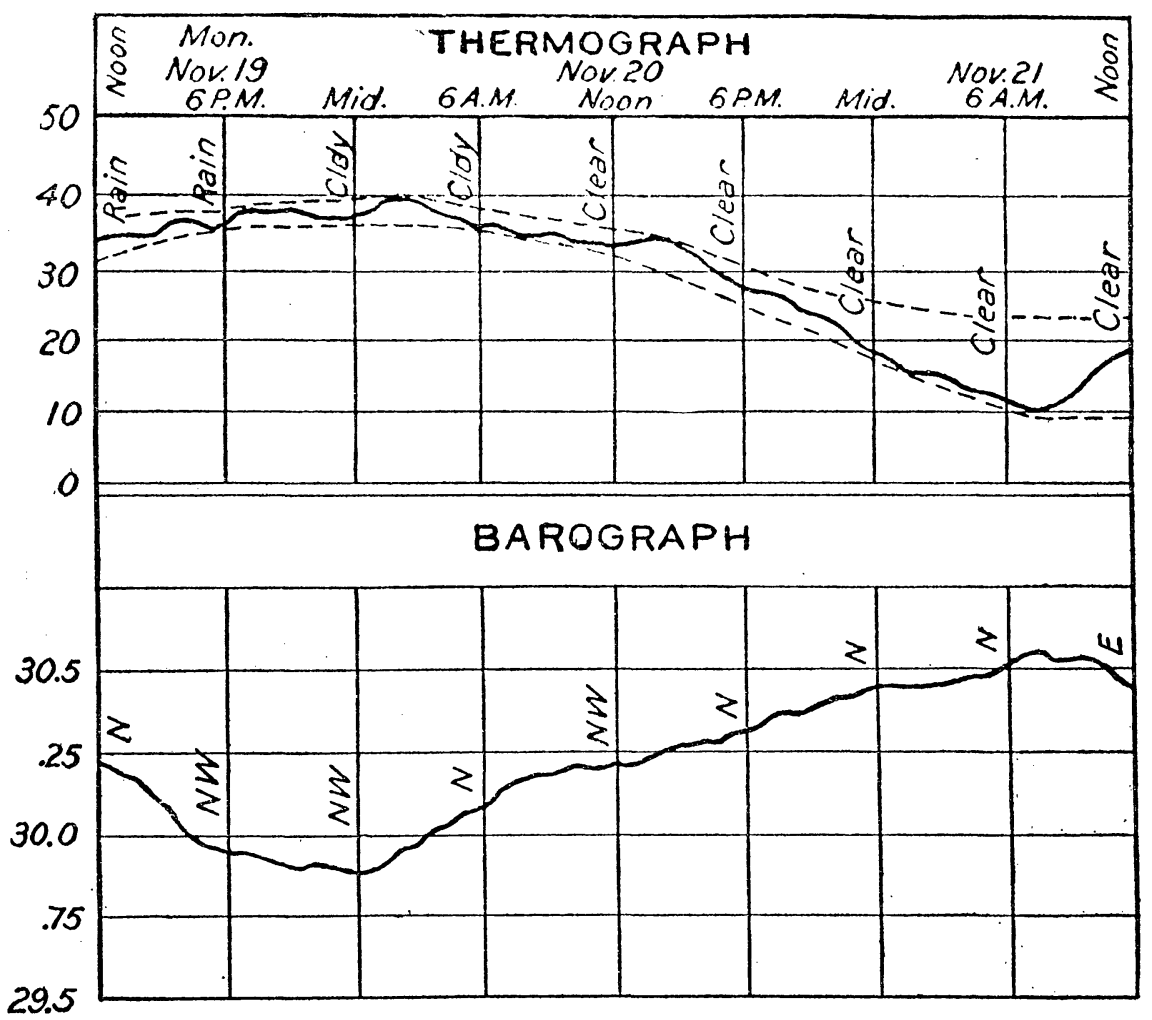

Fig. 41.-November cold spell. After a maximum temperature at night (November 19-20), a fall in temperature, beginning shortly after midnight, continues over noon (November 20), and until early in the morning of the following day. Such a fall of temperature over noon is one of the characteristic signs of approaching winter. The temperature belt is very narrow, showing slight ranges of temperature under the rain and cloudy sky of November 19, and widens under the clear skies and light winds of the anticyclone (November 21). The minimum temperature (November 21) comes under the clear sky of the anticyclonic night, with very light northerly winds.

lat. $50^{\circ} \mathrm{N}$ ), and then easterly, along the same path as that of the winter lows. Moderate anticyclones do not, however, dominate conditions to the eastward, as they seem to break up in the interior. As a high approaches, the north Pacific coast has cooler weather; increasing 
cloudiness in Washington and Oregon; perhaps showers west of the Cascades. Decreasing cloudiness, and higher temperatures prevail when the centre is north of the mouth of the Columbia River. As the high passes eastward across the Cascades, the sky clears, and the temperature rises, the maximum being recorded when the centre is northeast of Spokane. Hot, dry winds, occasionally injuring crops in Washington and Oregon, may occur under these pressure conditions, the warmest summer winds being north or northeast. When the anticyclone is well-marked over the north, and there is a well-developed low in southern California, hot northerly winds occur in the Sacramento and San Joaquin Valleys. The sequence of weather

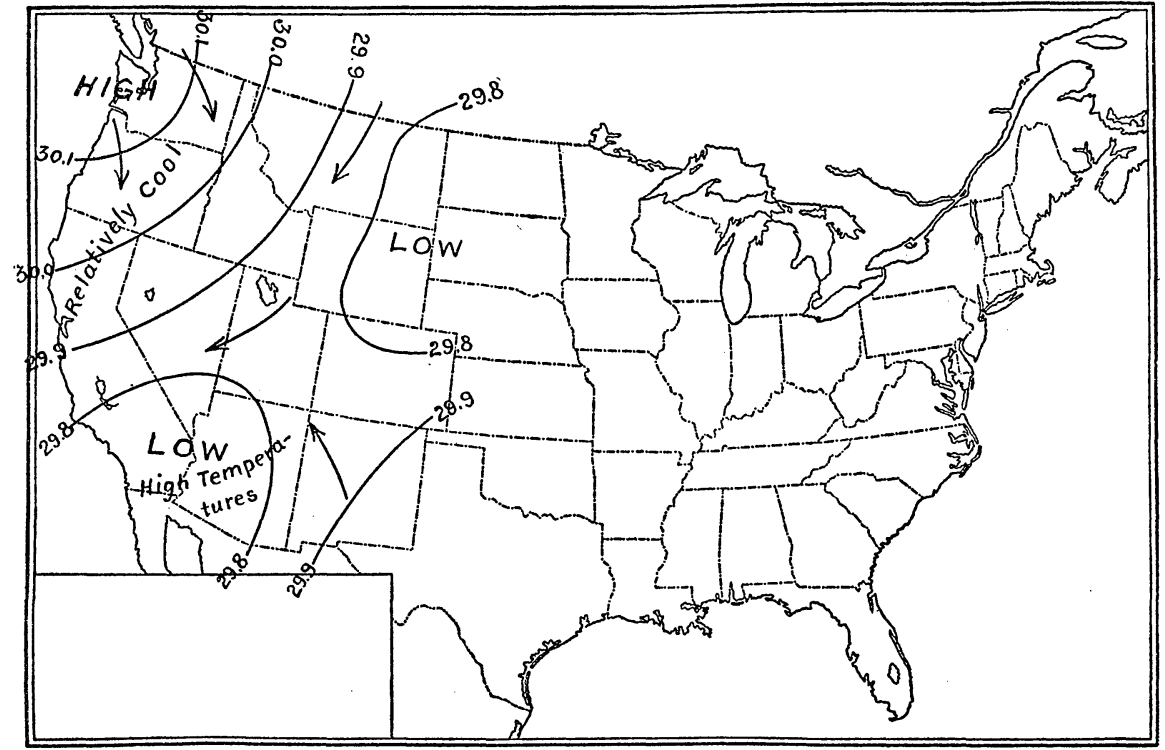

FIG. 42.-North Pacific Summer High.

changes accompanying the progression of a summer anticyclone from the coast of California to beyond the Rocky Mountains usually occupies about five to seven days. When these characteristic summer types of pressure distribution are later than usual, spring is retarded, and farming operations are delayed in northern sections. On the Pacific slope, as elsewhere, there is much weather which is not associated with any very definite cyclonic or anticyclonic conditions. Such types are intermediate, of a more or less nondescript character.

Winter Weather Types of the Western Interior Province.-The extended region between the Rocky Mountains and the Sierra NevadaCascades also has its own individual weather controls and weather types. In winter, especially in December and January, while much of the rest of the country is having unsettled and stormy weather, this 
western province, together with the Rocky Mountain districts generally, and the Great Plains, may have days and even weeks of fine, cold, dry weather, with generally light winds and marked diurnal variations of temperature, under the control of a persistent, stagnant, anticyclone which stands in the way of storms advancing from the Pacific Ocean, while a series of highs and lows passes along its eastern edge. Snow or rain falls around cyclones of the North Pacific type following the northern circuit across the Columbia Plateau, or in connection with those which cross the central or southern parts of the district on their eastward journey. The former being the more numerous, the northern portion of this province has heavier precipitation than the southern. The total precipitation which falls from such storms is, however, generally light, as the rain-shadow effect of the Pacific coast mountains, and the generally effective enclosure of the whole province would lead us to expect. The inflowing air currents lack the plentiful supply of water vapor which is characteristic of cyclonic circulation in the east, or on the northern Pacific coast. General cloudiness, rains, or snows, over the southern portion of the interior province come in connection with a cyclone which covers that district and is delayed in its eastward progress across the Rocky Mountains (Fig. 9). The area of clouds and of precipitation may also include the central and southern Rocky Mountain region. Cold waves are less frequent and less severe than over the region east of the Rocky Mountain barrier. In the north, they occur under well-marked anticyclonic controls, and are associated with northeasterly and northerly rather than with northwesterly winds, as is the case in eastern sections. In the middle and southern plateau regions they occur in the wake of deep low pressure areas moving across the Rocky Mountains, and are attended by high southwest to west winds. Cold, much below that common to the latitude, is generally developed. A low passing across the southern part of the Great Basin region followed by a high which moves southward over Idaho and Utah may bring killing frosts as far south as southern Arizona. The conditions of falling temperature move from north to south, often very rapidly, and may extend from the Pacific coast across the Rocky Mountains. When this air drainage is marked, the freezing line may extend as far south as the citrus region of California, as in the winter of 1913. High winds are common, and occur in winter and spring on steep cyclonic gradients.

Summer Weather Types of the Western Interior Province.-In place of the characteristic, more or less permanent winter anticyclone, the summer conditions over the Plateau and Basin province are marked by the presence of a fairly permanent and ill-defined low over the lower Colorado region,- - the so-called Yuma low. Anticyclones from 
the northwest temporarily interfere with this cyclonic control, and tend to emphasize the effect of this low, but the latter reestablishes itself as the highs move eastward. In fact, it is a sign of spring when the winter Rocky Mountain high pressure area weakens, and the low from the Gulf of California establishes itself. Summer weather over this great interior province is characteristically fine, and settled. Day after day the same uniform conditions prevail, especially in the southern section. Temperatures are high, especially in the south and at lower levels, but the greater elevations enjoy cooler nights, although the days are hot. The strong diurnal ranges of temperature, characteristic of this mountain and plateau country, with its prevailingly bright sunshine and dry air, may easily bring frost on the higher elevations during the clear nights of spring and early summer. Rainfall is generally light, the summer cyclones being weak and ineffective as rain-bearers. In the south, over southeastern California, Arizona, southern Utah and southern Nevada there is a more or less marked summer maximum, known locally as the "rainy season," and usually beginning early in July. These rains are essentially local thunderstorm rains, although they occur in connection with the general cyclonic trough of low pressure. Thunderstorms in Idaho come with the advance of low pressure areas from the northern interior of California.

Winter and Summer Weather Types of the Great Plains.-The Great Plains share to some extent in the weather types of the two regions which join them on the east and on the west. The great permanent winter anticyclone, west of the Continental Divide, referred to in a previous paragraph, extends its influence over the Great Plains area, giving much clear and settled winter weather. The temperatures east of the Divide, in the western Great Plains area, are usually mild under this anticyclonic control, with a succession of relatively dry, warm and bright sunny days, the prevailing winds being westerly, across the Continental Divide. At the same time it is intensely cold to the west of the mountains in the region dominated by the high. But the procession of winter cyclones keeps marching across the Plains chiefly in the north, and cold waves, gales, snows and blizzards sweep over the area. Sometimes the cyclones loop far south and severe conditions reach into New Mexico and Texas, damaging southern crops, and causing losses of cattle. Some of the most important storms of the Great Central Valley and the eastern United States originate in the Southwest and cross the Continental Divide in New Mexico. Sometimes the pressure barrier in the Rocky Mountain region is such that the Divide is crossed in Mexico. The storms then generally move northeastward. These lows give to the Plains region heavy snows, and with the eastward movement of the cyclone cold air from the Canadian 
Northwest sweeps southward along the eastern side of the Continental Divide. "Colorado type" storms may bring general cloudiness and precipitation over much of the Great Plains district (Figs. 16, 17). In summer, the Plains share with the rest of the country long spells of settled diurnal weather; with hot waves and drought not infrequently extending over many days, or even weeks; with thunderstorms bringing local temporary relief, and with occasional general storms bringing more widely distributed and beneficial rains. Easterly winds, climbing the mountain slopes toward the lower pressure areas of the interior province, give summer precipitation over the mountains to the west of the Plains. Well defined cyclonic areas are not cornmon over the central and southern Great Plains, and comparatively few cross the Continental Divide in the southern United States. Weak low pressure areas which succeed in reaching the eastern slope usually move northeast, developing as they travel eastward.

The foregoing description and illustration of some of our more important seasonal and regional weather types is manifestly incomplete and superficial. It is only by means of a careful examination of the daily weather maps, season by season, and year by year, that the student of the climatology of the United States can really make himself thoroughly familiar with these types. The suggestions here made will aid in such a detailed investigation.

NotE.-In Figs. 5-24 the light shading indicates cloudiness; the heavy shading shows areas of precipitation. 